\title{
ADSORPTION AT HIGH PRESSURES
}

\author{
P. G. MENON* \\ Regional Research Laboratory, Hyderabad-9, India \\ Received November $\%, 1967$
}

Con'tents

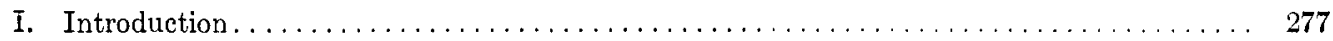

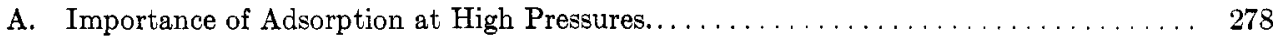

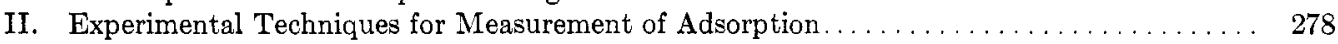

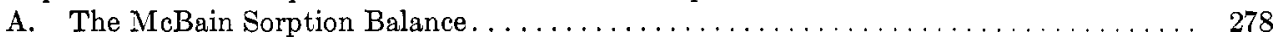

B. Method of Measuring Gas Volumes at Atmospheric Pressure . . . . . . . . . . . . . . . 279

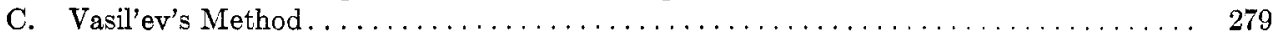

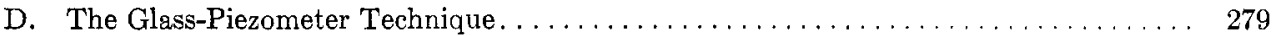

E. The Glass-Piezometer Technique for Pressures up to $3000 \mathrm{Atm} \ldots \ldots \ldots \ldots \ldots \ldots \ldots$

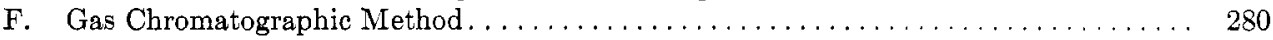

G. The Gravimetric Method $\ldots \ldots \ldots \ldots \ldots \ldots \ldots \ldots \ldots \ldots \ldots \ldots \ldots \ldots \ldots \ldots \ldots$

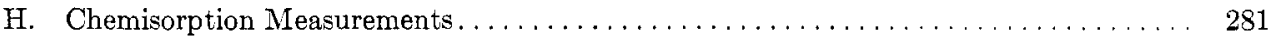

III. Corrections Considered in Adsorption Measurements . . . . . . . . . . . . . . . . . . . 281

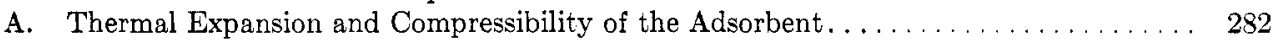

B. Dimensional Changes in Rigid Adsorbents on Physical Adsorption of Gases on Them.. 282

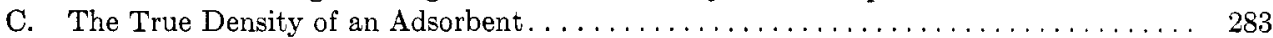

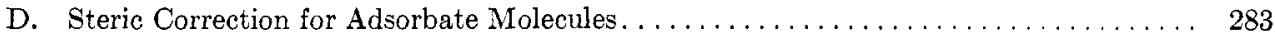

IV. Interpretation of Experimental Data on Adsorption at High Pressures . . . . . . . . . . . . 284

A. Adsorption above the Critical Temperature of the Adsorbate. . . . . . . . . . . 284

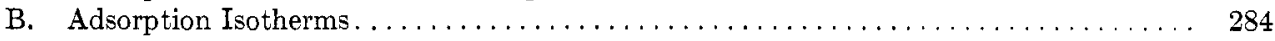

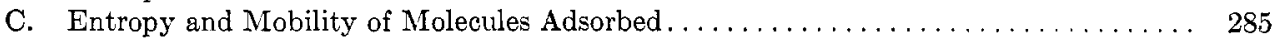

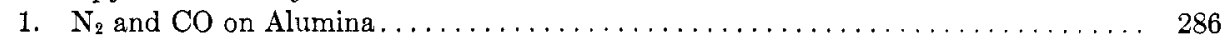

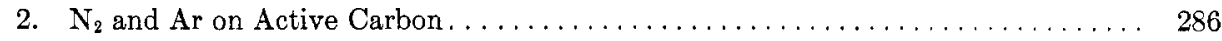

D. Decrease in Dead Space Due to the Volume of Adsorbed Molecules . . . . . . . . . . 286

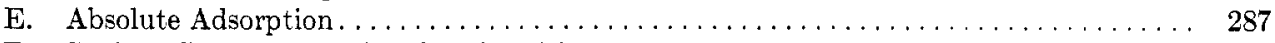

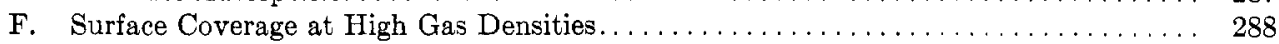

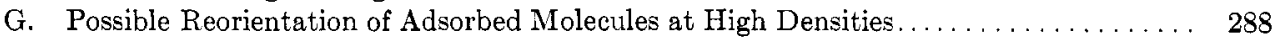

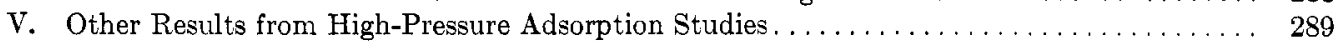

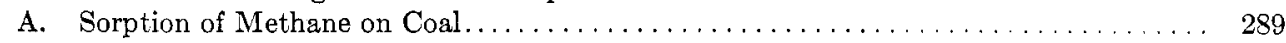

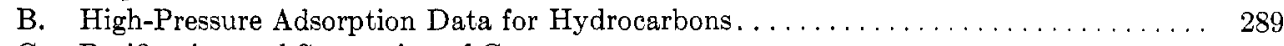

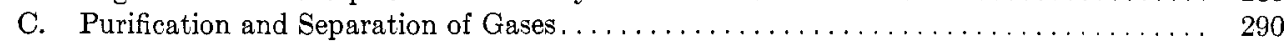

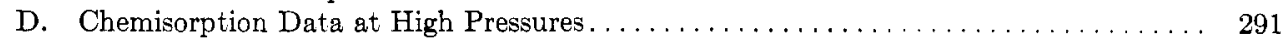

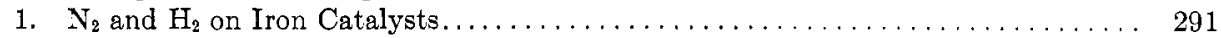

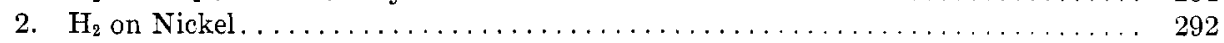

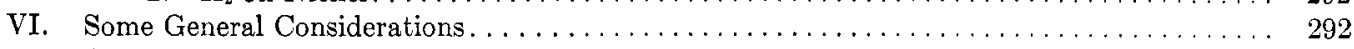

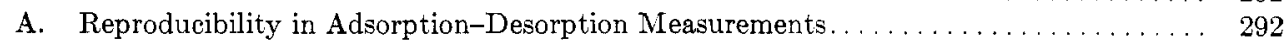

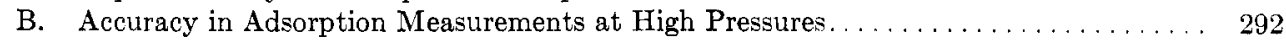

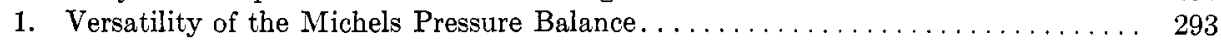

2. Helium-Density or Dead-Space Measurements.................... 293

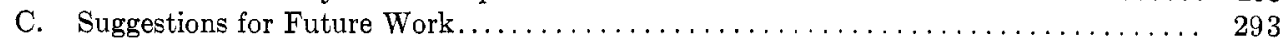

\section{IntRODUCTION}

Every year hundreds of papers are published on the adsorption of gases on solids at pressures below atmospheric, but data at high pressures are still very scarce. The main difficulty, in addition to experimental techniques; is "the rapidly growing inaccuracy and uncertainty of measurements where sorption is increasing only slowly with pressure and the amount of gas or vapor in the poorly defined dead space within the apparatus is rapidly becoming the dominant quantity

*Department of Chemical Engineering, Technological University Twente, Enschede, The Netherlands. observed." During the last 2 decades many types of equipment for generation and measurement of high pressures have become commercially available. This has led to a rapid increase in research in the field of high pressures; still adsorption studies at high pressures are few in number and often limited to medium pressures (up to $100 \mathrm{~atm}$ ). The pressure range for adsorption reached 3000 atm in only one laboratory and $1000 \mathrm{~atm}$ only in three other cases. In the period 1950-1965, only about 25 papers appeared on highpressure adsorption. All the important papers pub-

(1) J. W. MoBain and G. T. Britton, J. Am. Chem. Soc., 52, 2198 
lished between 1930 and 1966 have been covered by the present review.

McBain and Britton ${ }^{1}$ have given the adsorbents and adsorbates used, the temperature and pressure range covered, and important observations reported in the papers published before 1930 . Hence these papers are not covered in this review. The experimental techniques used in high-pressure adsorption work have been given only briefly here, since fuller details of these will soon be given in a forthcoming review. ${ }^{2}$ Greater emphasis is laid here on the results obtained from highpressure adsorption measurements and their interpretation, accuracy of the results, especially after the numerous corrections which have to be applied to them, and the physico-chemical significance of these results. Only adsorption of single gases has been considered here; multicomponent gas-solid equilibrium at high pressures will be dealt with elsewhere. ${ }^{2}$

\section{A. IMPORTANCE OF ADSORPTION AT HIGH PRESSURES}

Chemical reactions on an industrial scale in the 1000-3000-atm pressure range seem to be a definite possibility in the near future. The high-pressure synthesis of polyethylene and the Claude process for the synthesis of ammonia serve already as a pointer in this direction. An extension of pressure to the 3000-5000atm range in industrial chemical processes has even been anticipated, ${ }^{3}$ but one of the main hurdles in this development is our ignorance on the effect of pressure on catalytic activity. Though in some cases the effect of mechanical compression on solid catalysts up to 20,000 atm has been studied, ${ }^{4-6}$ the gas-solid interface under pressure has been little investigated. Since the adsorption of the reactant or reactants on the catalyst surface is a prerequisite for heterogenous catalytic reactions, how does this adsorption vary under high pressures? Even otherwise, adsorption studies at high pressures and relatively high temperatures may be a better approximation to actual conditions in industrial catalytic reactions than are the conventional lowpressure measurements.

But our knowledge of adsorption (be it physical or chemical) under reaction conditions is very scarce. Brunauer $^{7}$ has repeatedly pointed out the necessity of testing experimentally whether multimolecular adsorption above the critical temperature of the ad-

(2) P. G. Menon in "Advances in High Pressure Research," Vol. III, R. S. Bradley, Ed., Academic Press Inc., Oxford, in press.

(3) F. W. Wilson, Chem. Eng., 69, 195 (1962).

(4) O. D. Sterligov, M. G. Gonikberg, A. M. Rubinshtein, and B. A. Kazansky, Bull. Acad. Sci. USSR, Div. Chem. Sci., 25 (1953).

(5) L. Kh. Freidlin, L. F. Vereshchagin, L. E. Neimark, I. U. Numanov, and R. Y. Sheinfain, ibid., 84 (1953).

(6) I. Kh. Freidlin, L. F. Vereshchagin, and I. U. Numanov, Dokl. Akad. Nauk SSSR, 88, 1011 (1953); Chem. Abstr., 48, 13383 (1954).

(7) S. Brunauer, "The Adsorption of Gases and Vapours," Princeton University Press, Princeton, N. J., 1945, pp 336-338, 365, 442444 . sorbate and necessarily under high pressures is possible or not.

The sorption of methane by coal at high pressures has been investigated by several workers ( $c f$. section V.A). This still continues to be an important problem because of its direct bearing on explosion hazards in coal mines.

Chemisorption of gases and vapors on catalysts at high pressures is a field much more neglected than physical adsorption under high pressures. There seem to have been only three or four serious attempts so far in this direction (see section II.H), but the importance of this in heterogeneous catalytic processes under high pressures can never be overemphasized. In a review of kinetics of chemisorption of gases on solids, Low $^{8}$ has pointed out that the effect of pressure on chemisorption kinetics appears to be quite involved and controversial. It has been purposely neglected, preference being given to equilibrium studies. This was done because effects of pressure on rates were obvious. Low concludes, "This was wishful thinking and was probably brought about by too close mechanistic analogy to physical adsorption. In view of the importance of pressure effects to theory, much more work on this topic is justified."

High-pressure adsorption is being increasingly used in industry for purification of $\mathrm{H}_{2}$, separation of gases, particularly of light hydrocarbons obtained from processing of petroleum and natural gas, etc. This has actually motivated several new investigations in this field.

\section{Experimental Techniques for Measurement OF ADSORPTION}

\section{A. THE MCBAIN SORPTION BALANCE}

The earliest outstanding high-pressure adsorption work is the investigation of McBain and Britton ${ }^{1}$ on the sorption of $\mathrm{N}_{2} \mathrm{O}, \mathrm{C}_{2} \mathrm{H}_{4}$, and $\mathrm{N}_{2}$ on steam-activated sugar charcoal up to $50 \mathrm{~atm}$. The adsorbent, taken in a basket, was suspended from a quartz spiral, which was mounted in a thick-walled glass tube. The amount of gas adsorbed was determined gravimetrically from elongation of the calibrated spiral as measured with a precision cathetometer. The sorption balance was further refined for measuring the adsorption of propylene $^{9}$ and dimethyl ether ${ }^{10}$ on alumina near the critical temperatures and up to saturation pressure, of $\mathrm{CO}_{2}, \mathrm{~N}_{2} \mathrm{O}$, and $\mathrm{SiF}_{4}$ on charcoal up to $100 \mathrm{~atm},{ }^{11}$ and recently of $\mathrm{CO}_{2}$ on a porous plug of lampblack at 19,30 , and $32^{\circ}$ up to $80 \mathrm{~atm} .^{12}$

(8) M. J. D. Low, Chem. Rev., 60, 274 (1960).

(9) H. E. Morris and O. Maass, Can. J.Res., 9, 240 (1933).

(10) J. Edwards and O. Maass, ibid., 13B, 133 (1935).

(11) A. S. Coolidge and H. J. Fornwalt, J. Am. Chem. Soc., 56, 561 (1934).

(12) W. M. Jones, P. J. Isaac, and D. Phillips, Trans. Faraday Soc., $55,1953(1959)$. 
The great uncertainty factor in gravimetric measurement of adsorption at high pressures arises from the buoyancy correction to be applied to the observed results. For example, in the propylene adsorption isotherms of Morris and Maass, ${ }^{9}$ the buoyancy corrections at pressures of 32 and 39 atm are 50 and $80 \%$, respectively, of the "measured adsorption." This buoyancy correction is added to the observed adsorption to get the real adsorption. Moreover, it is not possible to go above $100 \mathrm{~atm}$ pressure, since the sorption balance has to be mounted in a glass tube to read optically the elongation of the quartz spiral spring. This difficulty has been partly overcome by mounting the quartz spiral in a steel apparatus with a Perspex window. ${ }^{13}$

Another disadvantage of the sorption balance has been pointed out recently. ${ }^{13}$ At and near the critical point, gradients of density can exist in the gaseous phase. Hence uncertainty can arise as to the value of the density in the vicinity of the bucket containing the adsorbent.

An analytical balance (Mettler Type H15) has also been modified for gravimetric measurement of adsorption at pressures up to $20 \mathrm{~atm}{ }^{14}$ The adsorption of $\mathrm{CH}_{4}$ and $\mathrm{C}_{2} \mathrm{H}_{6}$ on active carbon has been measured in this way. ${ }^{15}$ In this the analytical balance simply replaces the calibrated quartz spiral of the McBain sorption balance. Hence all the disadvantages and uncertainties of the sorption balance apply equally well to this, with the additional limitation of the rather too low pressure range obtained.

\section{B. METHOD OF MEASURING GAS VOLUMES AT ATMOSPHERIC PRESSURE}

Adsorption units with an all-steel side to handle the gas under pressure and a glass side to measure the volume of gas on expansion to 1 atm have been used by Frolich and White ${ }^{16}\left(\mathrm{H}_{2}\right.$ and $\mathrm{CH}_{4}$ on charcoal up to 150 atm at $25-100^{\circ}$ ), von Antropoff ${ }^{17}$ ( $\mathrm{Ar}$ and $\mathrm{N}_{2}$ on active carbon at $-76,-20,0$, and $20^{\circ}$ up to $400 \mathrm{~atm}$ ), and Moffat and Weale ${ }^{18}\left(\mathrm{CH}_{4}\right.$ on coal up to $\left.1000 \mathrm{~atm}\right)$. Strictly speaking, only the desorption isotherms are obtained in this way. The dead space in the adsorption vessel has been determined in very unsatisfactory ways. Frolich and White and von Antropoff have used copper shot of the same volume as the adsorbent and determined the so-called expansion isotherms. The volume of adsorbent itself was determined with helium at low pressures. Later von Antropoff ${ }^{170}$ determined the

(13) W. M. Jones and R. E. Evans, Trans. Faraday Soc., 62, 1596 (1966).

(14) B. Boehlen and A. Guyer, Helv. Chim. Acta, 47, 1815 (1964).

(15) B. Boehlen, W. Hausmann, and A. Guyer, ibid., 47, 1821 (1964).

(16) P. K. Frolich and A. White, Ind. Eng. Chem., 22, 1058 (1930).

(17) (a) A. von Antropoff, Kolloid-Z., 129, 11 (1952); (b) ibid.,

137, 105 (1954); (c) ibid., 137, 108 (1954); (d) ibid., 143, 98 (1955).

(18) D. H. Moffat and K. E. Weale, Fuel, 34, 469 (1955). density of the adsorbent using liquid nitrogen as the pycnometric liquid.

Czaplinski and Zielinski ${ }^{19}$ modified this method so that adsorption and not desorption isotherms could be directly measured. Known volumes of gas at 1 atm were introduced into a mercury-piston gas compressor, from which the gas was compressed into the adsorption vessel to get different initial pressures. The vessel was previously calibrated with helium. The decrease in pressure on cooling the vessel to liquid nitrogen temperature was noted. A blank experiment was conducted with the adsorption vessel filled with glass beads of the same volume as the adsorbent. From these data the adsorbed gas volume was calculated. In this way, the adsorption of $\mathrm{He}, \mathrm{Ne}$, and $\mathrm{H}_{2}$ was measured on active carbon ${ }^{19}$ and on two samples each of colloidal silica (BET surface areas 660 and $580 \mathrm{~m}^{2} / \mathrm{g}$ ) and alumina $\mathrm{a}^{20}\left(370\right.$ and $\left.350 \mathrm{~m}^{2} / \mathrm{g}\right)$ at liquid nitrogen temperature and up to $30 \mathrm{~atm}$. One serious source of error here can be from the unequal thermal contraction of the adsorbent and the dummy glass beads causing appreciable alteration of the dead-space volume.

\section{VASIL'EV'S METHOD}

An elegant method, which requires no compressor or oil press to raise the pressure or a gauge for measuring the high pressure, was used by Vasil' $e \mathrm{v}^{21}$ for the adsorption of $\mathrm{CO}_{2}$ on two types of silica at -85 to $40^{\circ}$ up to $80 \mathrm{~atm}$. In this method thermal compression was employed to obtain high pressures. A known amount of gas, measured at $1 \mathrm{~atm}$, was transferred into a calibrated steel U-tube cooled in liquid nitrogen. The coolant was removed and the U-tube was opened to the evacuated adsorption vessel, the helium dead space of which was already known. At equilibrium the U-tube was isolated from the vessel and the gas in it was measured after expansion to 1 atm. From these data, the amount of $\mathrm{CO}_{2}$ adsorbed and also the equilibrium pressure were calculated using the accurate compressibility data ${ }^{22,23}$ for $\mathrm{CO}_{2}$. Details of this method given in English ${ }^{24}$ have also been reproduced in a recent monograph. ${ }^{25}$

\section{THE GLASS-PIEZOMETER TECHNIQUE}

The glass-piezometer type of apparatus used for the study of the sorption of methane on coal up to 500

(19) A. Czaplinski and E. Zielinski, Przemysl Chem., 37, 640 (1958).

(20) A. Czaplinski and E. Zielinski, ibid., 38, 87 (1959).

(21) B. N. Vasil'ev Zh. Fiz. Khim., 31, 498 (1957).

(22) A. Michels and C. Michels, Proc. Roy. Soc. (London), A153, 201 (1935)

(23) A. Michels, C. Michels, and H. Wouters, ibid., A153, 214 (1935)

(24) M. M. Dubinin, S. P. Bering, V. V. Serpinski, and B. N. Vasil'ev in "Surface Phenomena in Chemistry and Biology," Pergamon Press, New York, N. Y., 1958, pp 172-188.

(25) S. Ross and J. P. Olivier, "On Physical Adsorption," Inter. science Publishing Corp., New York, N. Y., 1964, pp 72-75. 
$a^{26}$ represents a significant advance in technique. The calibration of the volumes of the piezometer bulbs with mercury and the use of the Michels pressure balance $e^{27-29}$ for measuring pressure have ensured much higher accuracy than in any previous work in this field. This work is in a way the forerunner of the technique described below.

\section{E. THE GLASS-PIEZOMETER TECHNIQUE FOR PRESSURES UP TO 3000 ATM}

During the last 4 decades highly specialized techniques for the accurate measurement of $P-V-T$ relations of gases up to $3000 \mathrm{~atm}$ had been developed by Michels in the van der Waals Laboratory in Amsterdam. Taking advantage of these techniques, a new method was developed ${ }^{30-32}$ for accurate study of the adsorption of gases on solids. Three distinctive features of this method over the earlier high-pressure adsorption measurements are (1) the adsorbent and the adsorbate gas were enclosed in glass and not in metal even at a pressure of $3000 \mathrm{~atm}$; (2) the use of the Michels pressure balance ensured an accuracy of 1 in 10,000 in pressure measurements; (3) the compressibility isotherm data for the adsorbate gases were determined earlier in the same laboratory, using the same techniques and almost identical apparatus as for the highpressure adsorption work.

The main difference between the adsorption measurements and the usual gas-compressibility measurements was that in the former a glass capsule containing an adsorbent under vacuum was enclosed in the top bulb of the glass piezometer. From two $P-V$ measurements (below $20 \mathrm{~atm}$ ), the volume of the top bulb (outside the capsule) and also the amount of gas taken in the piezometer were determined. On raising the pressure to about $30 \mathrm{~atm}$, a thin diaphragm on the capsule was broken and the adsorbent was made accessible to the adsorbate gas. From pressure measurements at the different platinum contacts, located between the successive calibrated volumes of the piezometer, the amount of gas left over at that gas pressure was calculated using the compressibility data for the gas. From this the amount of gas which had apparently disappeared due to adsorption was obtained. The pressure range was raised to 3000 atm in overlapping stages of gas filling, the adsorption-desorption cycle for any gas filling being fully reversible and re-

(26) J. van der Sommen, P. Zwietering, B. J. M. Eillebrecht, and D. W. van Krevelen, Fuel, 34, 444 (1955).

(27) A. Michels, Ann. Physik, 72, 285 (1923); 73, 577 (1924)

(28) A. Michels, Proc. Roy. Acad. Sci., Amsterdam, 26, 805 (1923); 27,930 (1924).

(29) At present made and marketed by 'tHart \& $\mathrm{Zn}$, Rotterdam. (30) A. Michels, P. G. Menon, and C. A. ten Seldam, Rec. Trav. Chim., 80, 483 (1961).

(31) P. G. Menon, "Adsorption of Nitrogen and Carbon Monoxide on Alumina up to 3000 Atmospheres Pressure," Thesis, Delft, 1961.

(32) P. G. Menon, J. Am. Chem. Soc., 87, 3057 (1965). producible. In this way the adsorption of mass spectrometrically pure $\mathrm{N}_{2}$ and $\mathrm{CO}$ on an alumina sample (surface area $120 \mathrm{~m}^{2} / \mathrm{g}$ ) was determined up to 3000 atm at $-76,0,25,50,75$, and $100^{\circ}$ for $\mathrm{N}_{2},{ }^{30}$ and at 0,25 , and $50^{\circ}$ for $\mathrm{CO} .^{32}$ Adsorption of $\mathrm{N}_{2}$ on another alumina sample (surface area $94 \mathrm{~m}^{2} / \mathrm{g}$ ) was also determined ${ }^{30}$ at $0,50,75$, and $100^{\circ}$ up to 500 atm using only one gas filling.

The volume of alumina inside the capsule was calculated from the helium density of alumina measured in a low-pressure adsorption apparatus. The dead space inside the capsule was taken as the difference between the external volume of the capsule and the sum of the volume of the glass of the capsule and of the alumina in it.

\section{F. GAS CHROMATOGRAPHIC METHOD}

A gas chromatographic apparatus modified for highpressure operation has been described by Stalkup and Kobayashi. ${ }^{33}$ Using it, the measurement of vaporsolid distribution coefficients or $K$ values of a solute distributed between a gas phase and an adsorbed phase at essentially infinite dilutions has been carried out ${ }^{34}$ for $\mathrm{C}_{2} \mathrm{H}_{4}, \mathrm{C}_{3} \mathrm{H}_{8}$, and $n-\mathrm{C}_{4} \mathrm{H}_{10}$ in a $\mathrm{CH}_{4}$-silica gel system up to 2000 psi. The method has been extended to a study of multicomponent gas-solid equilibrium at high pressures, ${ }^{35}$ with $\mathrm{CH}_{4}-\mathrm{C}_{3} \mathrm{H}_{8}$-silica gel as a typical example for pressures up to 1000 psi. The total adsorption, component adsorption, and the $K$ value for each component are related to the retention volume for the components as measured by a technique which distinguishes the molecules in the elution gas from those in the perturbing sample. Radioactively traced hydrocarbons are used to obtain the appropriate retention volumes.

Application of the chromatographic technique with radioactive samples to the study of mixtures eliminates the necessity for calibrating the system volume with helium and for sampling the gas phase. The data obtained are shown to be consistent with those from a gravimetric method ( $c f$. section III.G) and infinitedilution adsorption $K$ values.

A simpler and more straightforward gas-chromatographic flow method ${ }^{36}$ is based on a material balance as the components are transported by a carrier gas through an adsorbent-packed column. The adsorption of hydrocarbon gas mixture on silica gel up to 120 atm is a typical example. The column is packed with a weighed quantity of adsorbent that has been heated to $260^{\circ}$ for $3 \mathrm{hr}$. After the column is purged with a carrier gas and the pressure adjusted, flow is diverted to a bypass line while composition of the inlet stream

(33) F. I. Stalkup and R. Kobayashi, A.I.Ch.E. J., 9, 121 (1963).

(34) H. B. Gilmer and R. Kobayashi, ibid, 10, 797 (1964).

(35) H. B. Gilmer and R. Kobayashi, ibid., 11, 702 (1965).

(36) J. P. Mason and C. E. Cooke, Jr., ibid., 12, 1097 (1966). 
is adjusted. When the desired composition is reached, the flow is turned on into the adsorption column. Samples of the outlet gas from the column are withdrawn periodically and analyzed gas chromatographically until their composition becomes steady and equal to that of the inlet gas. An adsorption breakout curve is obtained from a plot of composition vs. time. For desorption, pure carrier gas is passed through the column until the exit-gas analysis shows no trace of the component gases being studied. A desorption breakout curve is thus obtained.

The area behind the breakout curve is proportional to the quantity of the component adsorption at the concentration of the inlet gas and the temperature and pressure of the column. In this way the adsorption of all components other than the carrier can be determined in any gas mixture. However, because of reequilibrium between gaseous and adsorbed phases as successive adsorption fronts move along the adsorbent column, the column must be saturated with the most highly adsorbed component before the breakout curve for any component is complete.

For binary gas mixtures, Eberly ${ }^{37}$ has shown that the values of adsorption for the heavier component at all levels of concentration up to that of the mixture can be calculated from a single desorption breakout curve. This method has been used by Mason and Cooke ${ }^{36}$ for measuring adsorption (on silica gel) of ethane, propane, isobutane, $n$-butane, isopentane, $n$-pentane, and $n$-hexane in binary mixtures with methane. The adsorption breakout curve was used for all components heavier than methane in multicomponent mixtures of these hydrocarbons.

The gas chromatographic method at medium pressures can be made the basis for determination of adsorption isotherms or of surface areas of catalysts. In Haley's extension ${ }^{38}$ of the Nelsen-Eggertsen continuous flow method, ${ }^{39}$ a mixture of $10 \% \mathrm{~N}_{2}$ in $\mathrm{He}$ is passed over the sample cooled in liquid nitrogen at a fixed rate at various pressures up to $10 \mathrm{~atm}$, causing the $\mathrm{N}_{2}$ partial pressure to reach its liquefaction point. Nitrogen adsorbed or desorbed by increasing or decreasing pressure in the sample tube is measured continuously (at atmospheric pressure) by thermal conductivity with a reference stream of $10 \% \mathrm{~N}_{2}$ in $\mathrm{He}$. Isotherms determined by this method show good agreement with those determined by conventional volumetric adsorption measurements. The new method does not involve vacuum techniques; it gives a permanent record automatically, is faster and simpler for routine application, and requires less skill.

(37) P. E. Eberly, J. Phys, Chem., 65, 1261 (1961).

(38) A. J. Haley, J. Appl. Chem., 13, 392 (1963).

(39) F. M. Nelsen and P. T. Eggertsen, Anal. Chem., 30, 1387 (1958).

\section{G. THE GRAVIMETRIC METHOD}

Gilmer and Kobayashi ${ }^{34}$ in their study of gas-solid equilibrium at high pressures by gas chromatography used a direct gravimetric method to determine the adsorption isotherms of their carrier gas, methane, on silica gel at $-40,-20,0,20$, and $40^{\circ}$ up to $140 \mathrm{~atm}$. It consisted of first equilibrating the chromatograph column by a steady flow of methane through it at the desired temperature and pressure, then closing off the column with valves at both ends, removing the assembly from the rest of the system, and weighing it on an analytical balance. The mass of total gas (gas adsorbed plus that in equilibrium in the gaseous phase) in the column would be the difference between the weight of the column assembly and that when it was evacuated. The mass adsorbed was obtained by subtracting from this difference the product of the free volume in the column and the gas density at the equilibrium conditions of temperature and pressure. The free volume in the column was determined with helium.

\section{H. CHEMISORPTION MEASUREMENTS}

Only very little has been done on the chemisorption of gases on solids at high pressures. Emmett and Brunauer $^{40}$ have studied the chemisorption of $\mathrm{N}_{2}$ on a doubly promoted iron-synthetic ammonia catalyst up to $50 \mathrm{~atm}$. Their method consists in chilling the adsorption equilibrium from high pressure and high temperature to $1 \mathrm{~atm}$ and room temperature, reduction of the chemisorbed $\mathrm{N}_{2}$ by $\mathrm{H}_{2}$, and subsequent estimation of the ammonia so formed. Here desorption of $\mathrm{N}_{2}$ may occur during the chilling process. Furthermore, one cannot be sure that the whole of the chemisorbed $\mathrm{N}_{2}$ will be readily converted to ammonia. Sastri and Srikant ${ }^{41,42}$ have used an improved version of the volumetric technique of Frolich and White; ${ }^{16}$ the adsorption of $\mathrm{N}_{2}$ and $\mathrm{H}_{2}$ and of a $3 \mathrm{H}_{2}: 1 \mathrm{~N}_{2}$ mixture has been measured on a commercial synthetic ammonia catalyst (Aerocat) at $97-400^{\circ}$ and up to $50 \mathrm{~atm}$. A volumetric technique similar to that of Vasil'ev' has been employed by Vaska and Selwood ${ }^{43}$ for simultaneous measurement of hydrogen chemisorption and specific magnetization up to $140 \mathrm{~atm}$ on a supported nickel catalyst.

\section{Corrections Considered in Adsorption Measurements}

The corrections to be applied in high-pressure adsorption work will depend on the experimental technique being employed. In the McBain sorption

(40) P. H. Emmett and S. Brunauer, J. Am. Chem. Soc., 56, 35 (1934)

(41) M. V. C. Sastri and H. Srikant, J. Sci. Ind. Res. (India), 20D, 321 (1961).

(42) H. Srikant, Thesis, Madras University, 1954.

(43) L. Vaska and P. W. Selwood, J.Am. Chem. Soc., 80, 1331 (1958). 
balance, the buoyancy correction is the most important. In the more common volumetric methods, where the deadspace volume in the apparatus is determined with helium at about atmospheric pressure, two important corrections will be to account for the change in the volume of the apparatus and hence of the dead-space volume at the different temperatures and pressures in the experiments. Some other corrections which may become relevant at high pressures are discussed below.

\section{A. THERMAL EXPANSION AND COMPRESSIBILITY} OF THE ADSORBENT

The coefficients of thermal expansion and compressibility are not known for most of the adsorbents tried so far. Hence it is not possible to apply any correction to the dead-space volume in the apparatus to account for these two factors. However, the order of magnitude of these corrections can still be roughly calculated.

The volume expansion of alumina (corundum) ${ }^{44}$ from 20 to $100^{\circ}$ is $0.14 \%$. In the study of the highpressure adsorption of $\mathrm{N}_{2}$ on alumina, ${ }^{30}$ the volume expansion for the temperature range $20-100^{\circ}$ for $3.9657 \mathrm{~g}$ of alumina of helium density $3.359 \mathrm{~g} / \mathrm{cm}^{8}$ will be $0.00165 \mathrm{~cm}^{3}$ if the above value for corundum is applicable to partially dehydrated alumina. At a gas density of 572 amagats $^{45}$ (the highest density reached in the measurements at $100^{\circ}$ corresponding to a pressure of $2480 \mathrm{~atm}$ ), this volume expansion can cause an error of about $0.9 \mathrm{~cm}^{3}$ in the observed adsorption of $23.5 \mathrm{~cm}^{3}$, i.e., an error of $3.8 \%$. At lower densities and lower temperatures the error will be much less.

The order of magnitude of the compressibility of metallic elements and ionic lattices can be calculated ${ }^{46}$ from the relation (per atmosphere)

$$
-\frac{\Delta V}{V_{0}}=8.6 \times 10^{-14}(M / d)^{4 / 3}
$$

where $M$ is the atomic or molecular weight of the adsorbent and $d$ is its density. For the alumina with a helium density of $3.359 \mathrm{~g} / \mathrm{cm}^{8},-\Delta V / V_{0}=8.137 \times$ $10^{-8}$. For $3.9657 \mathrm{~g}$ of alumina in the high-pressure adsorption measurements, ${ }^{30}$ the change in volume at $3000 \mathrm{~atm}$ will be

$-\Delta V=\frac{3.9657}{3.359} \times 3000 \times 8.137 \times 10^{-8}=$

and hence negligible.

$2.88 \times 10^{-4} \mathrm{~cm}^{3}$

(44) F. Birch, et al., Ed., "Handbook of Physical Constants," Geological Society of America, Washington, D. C., Special Papers, No. $36,1954, \mathrm{pp} 31,54$.

(45) One amagat unit of density $=$ the density of the gas at $0^{\circ}$ and 1 international atmosphere pressure.

(46) P. W. Bridgman, "The Physics of High Pressure," G. Bell \& Sons Ltd., London, 1949, Chapter VI.
Thus, the corrections due to thermal expansion and compressibility are not appreciable for an adsorbent which is a hard abrasive solid like alumina, but, for relatively less hard adsorbents like active carbon or coal, these two corrections may not be negligible, particularly above $500 \mathrm{~atm}$.

\section{B. DIMENSIONAL CHANGES IN RIGID ADSORBENTS ON PHYSICAL ADSORPTION OF GASES ON THEM}

Chemisorption of a gas on a solid seriously alters the adsorbent surface, but, in physical adsorption, the concept of inert adsorbents is generally taken for granted mainly for simplifying any theoretical treatment into that of a one-component system. As Brunauer, Kantro, and Weise ${ }^{47}$ have pointed out, "the theoretical arguments advanced in favour of this assumption (of inert adsorbent) are inadequate and experimental data wholly lacking" (see also Brunauer ${ }^{48}$ and Yates and Sheppard ${ }^{49}$ ). Volume changes in rigid adsorbents on adsorption have been studied by several workers. ${ }^{50}$ More refined measurements were carried out in Ottawa $a^{52-56}$ and in Cambridge. ${ }^{57-59}$ The dimensional changes measured for rigid solids like active carbon rod or porous glass when rare gases are adsorbed on them provide direct evidence that the assumption of inert adsorbents in physical adsorption is invalid. This problem has been discussed in greater detail in an excellent review on molecular specificity in physical adsorption by Yates. ${ }^{51}$ The present discussion is confined only to the possible change in the dead space volume (in a high-pressure adsorption apparatus) caused by any dimensional change of the adsorbent on adsorption of gases on it.

The order of magnitude of the dimensional change has also been discussed by Yates. ${ }^{51}$ The conclusion is that the absolute dimension change due to adsorption is small, but in rigid solids it is not negligible in comparison with other processes (like thermal expansion or compressibility) affecting the size of the solid.

Contraction of the adsorbent solid on adsorption has been found to occur in cases where hydrogen bonding can take place between the adsorbate and $\mathrm{OH}$ groups on adsorbent..$^{51}$ The stronger the hydrogen bond formed, the larger is the contraction.

(47) S. Brunauer, D. L. Kantro and C. H. Weise, Can. J. Chem., 34, 729 (1956).

(48) S. Brunauer, Proceedings of the 2nd International Congress on Surface Activity, Butterworth \& Co., Ltd., London, 1957, p 17.

(49) D. J. C. Yates and N. Sheppard, ref 48, p 27.

(50) These references to earlier work are given by Yates. ${ }^{51}$

(51) D. J. C. Yates, Advan. Catalysis, 12, 265 (1960).

(52) C. H. Amberg and R. McIntosh, Can. J. Chem., 30, 1012 (1952).

(53) H. W. Quinn and R. MeIntosh, ibid., 35, 745 (1957).

(54) E. A. Flood, ibid., 35, 48 (1957).

(55) E. A. Flood and R. D. Heyding, ibid., 32, 660 (1954).

(56) M. L. Lakhanpal and E. A. Flood, ibid,, 35, 887 (1957).

(57) D. J. C. Yates, Proc. Roy. Soc. (London), A224, 526 (1954)

(58) D. J. C. Yates, J. Phys. Chem., 60, 543 (1956).

(59) D. J. C. Yates, Advan. Catalysis, 9, 481 (1957). 
A third type of dimensional change in an adsorbent on adsorption can be caused by the penetration of adsorbed molecules into the interlamellar space in the adsorbent, as in the case of sorption of methane on coal at high pressures. This interstitial penetration is accompanied by a slight expansion of the coal structure which has been measured ${ }^{18}$ by electrical resistance strain gauges attached to suitably cut blocks of coal. No expansion takes place in compressed helium nor is it seen when the coal sample is encased in metal which mechanically prevents expansion.

\section{THE TRUE DENSITY OF AN ADSORBENT}

A serious criticism of all high-pressure adsorption work arises from the use of helium to determine the dead space in the container for the adsorbent and using this dead-space value without any correction to adsorption measurements. The concept of helium density of an adsorbent is itself open to question. As Coolidge and Fornwalt ${ }^{11}$ have pointed out, no experiment on the displacement of any fluid by an adsorbent will give the density unless some assumption is made concerning the amount of adsorption that occurs, and a definition based on such an assumption cannot logically be used to determine the adsorption itself. Since the adsorption of helium on ordinary solid surfaces is in general negligibly small at room temperature and even up to $100 \mathrm{~atm}$, helium has been extensively used for dead-space calibrations in volumetric adsorption measurements. There does not to seem be any better method for this purpose at present.

de Boer and Steggerda ${ }^{60}$ have discussed the corrections to the helium density of microporous substances arising from (a) the dimension of the helium atom itself, and (b) the slight adsorption of helium. These corrections become appreciable for adsorbents of high surface areas. Corrections for these two factors can be accurately estimated only if the absolute surface area $S$ of the adsorbent, the distance $r$ between the center of the impinging helium atom and the surface, and the heat of adsorption of helium on the surface are known with certainty.

The BET surface area may be a sufficiently accurate approach to the real surface area of an adsorbent, but the distance $r$ is inaccurately known. ${ }^{61}$ Its value may, perhaps, be dependent on the mutual attraction between a helium atom and the adsorbent surface and vary from one adsorbent to another and also at different energetically heterogenous sites on one and the same adsorbent. The heat of adsorption of helium is also unknown in most cases.

Approximate corrections to the helium density value can still be made to account for the dimension of the

(60) J. H. de Boer and J. J. Steggerda, Koninkl. Ned. Akad. Wetenochap., Proc., B61, 317 (1958).

(61) J. H. de Boer, Advan. Catalysis, 8, 24 (1956). helium atom itself and the slight adsorption of helium. These corrections are of opposite sign. If the heat of adsorption of helium on the adsorbent is between 650 and $750 \mathrm{cal} / \mathrm{mole}$, the two corrections nearly counterbalance each other. ${ }^{60}$

If the actual dimension of the helium atom is considered, the center of the atom cannot approach the adsorbent surface closer than the radius $r_{\text {He }}$ of the helium atom. Hence all over the surface $S$ of the adsorbent there is a thin layer of thickness $r_{\mathrm{He}}$ into which the centers of helium atoms cannot penetrate. Consequently, the real specific volume of the adsorbent will be less than the experimentally measured one using helium by the quantity $S r_{\mathrm{He}}$. The dead space in the apparatus measured with helium will be less than the true dead space by $S w_{\text {He, }}$, where $S$ is the surface area of the adsorbent per gram and $w$ is the weight of the adsorbent taken in the apparatus. For alumina, the value of $1.2 \AA$ has been suggested for $r_{\mathrm{He}}$ by de Boer and Steggerda;60 this value includes a correction for the slight adsorption of helium with a heat of adsorption of roughly $100 \mathrm{cal} / \mathrm{mole}$.

\section{STERIC CORRECTION FOR ADSOR BATE MOLECULES}

The steric corrections discussed above for helium also have to be applied to the adsorbate molecules, the centers of which cannot approach a surface closer than the molecular radius. ${ }^{62}$ Hence the free volume accessible to the adsorbate molecules in the piezometer is less than the absolute volume by the quantity $\mathrm{Swr}_{\mathbf{n}}$, where $r_{a}$ is the radius of the adsorbate molecule. The net result is a decrease in the original dead space value by $\Delta v$

$$
\Delta v=S w\left(r_{\mathrm{s}}-r_{\text {He }}\right)
$$

where $r_{\mathrm{a}}$ may be calculated from the van der Waals constant $b$ for the adsorbate gases or, perhaps, from the second virial coefficient for the gases. For an adsorbent with $S=100 \mathrm{~m}^{2} / \mathrm{g}, \Delta v$ is of the order of $0.003-0.004 \mathrm{~cm}^{3} / \mathrm{g}$.

In conclusion it may be pointed out that the special corrections discussed in section III are negligibly small in most low-pressure adsorption measurements. Even up to a gas density of 150-250 amagats (the range in which high-pressure adsorption isotherms exhibit a maximum), their influences are not very marked on the over-all high-pressure adsorption results, but in the higher density region, especially above 350 amagats, they become important and even decisive for the interpretation of the results. Most of these corrections can be calculated only approximately. The most serious limitation is the lack of an accurate experimental method, to measure the exact distance of the center

(62) Polarization of the adsorbate molecule by the field of force of the adsorbent surface may also have to be taken into account in a rigorous treatment of this steric correction. 
of an adsorbed atom or molecule from the adsorbent surface. As de Boer ${ }^{61}$ has pointed out, this distance will be nearly double if the surface is regarded as a plane passing through the centers of surface atoms instead of one passing through the peripheries of these atoms. Most of the forces which cause adsorption depend very much on this distance, about which so little is known.

IV. Interpretation of Experimental Data on Adsorption at High Pressures

\section{A. ADSORPTION ABOVE THE CRITICAL TEMPERATURE OF THE ADSORBATE}

Above the critical temperature of a gas, saturation of an adsorbent with physically adsorbed molecules of the gas can be attained only at high pressures. The farther the experimental temperature is above the critical temperature, the higher will be the pressure required to attain an appreciable surface coverage. For gases like $\mathrm{N}_{2}$ and $\mathrm{CO}\left(T_{\mathrm{o}}=-147\right.$ and $-140.3^{\circ}$, respectively), pressures of $150-250 \mathrm{~atm}$ will have to be applied at $25^{\circ}$ to get a surface coverage of $0.3-0.4$ on alumina of surface area $120 \mathrm{~m}^{2} / \mathrm{g}$.

According to Brunauer, ${ }^{7}$ most adsorption isotherms obtained for gases above the critical temperature represent adsorption on "active" parts of the heterogenous surface.

\section{B. ADSORPTION ISOTHERMS}

If the measurements have been carried out to sufficiently high pressures, the adsorption isotherms always exhibit a maximum. Such maxima have been reported by many workers. As typical examples, the adsorption isotherms for $\mathrm{N}_{2}$ and $\mathrm{Ar}$ on active carbon and $\mathrm{N}_{2}$ and $\mathrm{CO}$ on alumina are shown in Figures 1-4. At higher pressures, the density of the gas is a better basis than pressure for comparison of adsorption at different temperatures. This can be seen from Table I where

TABLE I

Pressures of $\mathrm{N}_{2}$ at Different Temperatures for Nearly

$\begin{array}{rcc}\text { Temp, }{ }^{\circ} \mathrm{C} & \begin{array}{c}\text { THE SAME Density } \\ \text { Pressure, atm }\end{array} & \text { Density, amagats } \\ -0.76 & 111.14 & 112.90 \\ 99.71 & 164.68 & 112.99 \\ -0.76 & 1687.69 & 572.74 \\ 74.90 & 2291.38 & 572.58 \\ 99.71 & 2480.42 & 572.29 \\ -0.76 & 2592.18 & 643.89 \\ 25.09 & 2870.59 & 643.24\end{array}$

the rapid increase of pressure with increasing temperature for almost the same density is shown for $\mathrm{N}_{2}$ (taken from Table IV of ref 30 ).

The maximum in adsorption isotherms at high pressures is only to be expected. According to the ordinary

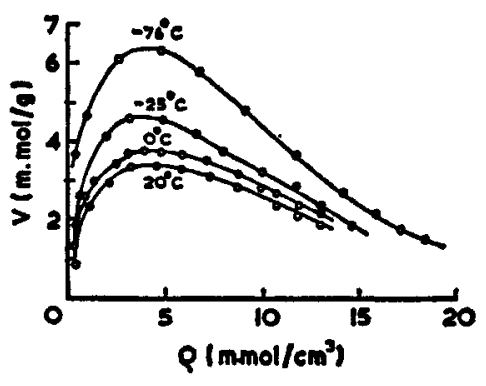

Figure 1.-Adsorption of $\mathrm{N}_{2}$ on active carbon at high gas densitieg (pressures up to $400 \mathrm{~atm}$ ) (data of von Antropoff ${ }^{17}$ ).

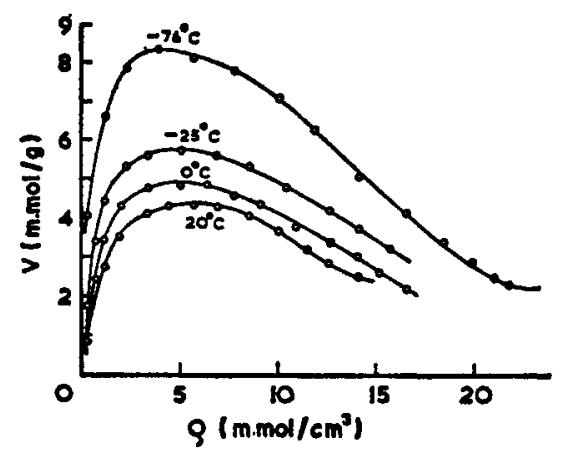

Figure 2.-Adsorption of argon on active carbon at high gas densities (pressures up to $400 \mathrm{~atm}$ ) (data of von Antropoff ${ }^{17}$ ).

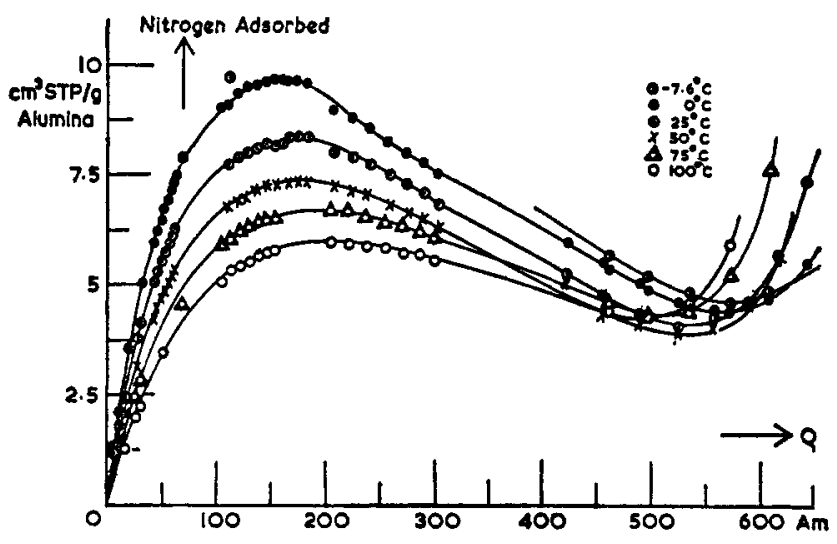

Figure 3.-Adsorption of $\mathrm{N}_{2}$ on alumina at high gas densities (pressures up to $3000 \mathrm{~atm}$ ). Densities are in amagat units (data of Michels, Menon, and ten Seldam ${ }^{30}$ ).

definition of adsorption, the amount adsorbed is the excess material present in the pores and on the surface of the adsorbent over and above that corresponding to the density of the gas in the bulk phase at that temperature and pressure. With increasing pressure this excess or differential adsorption soon reaches a maximum. As the pressure is increased further, the density of the gas phase $\left(\rho_{\mathbf{g}}\right)$ gradually approaches that of the adsorbed phase $\left(\rho_{\mathrm{a}}\right)$. In principle, this can continue until $\rho_{\mathrm{g}}=\rho_{\mathrm{a}}$, and the amount adsorbed measured experimentally and calculated according to the above definition must become zero. Hence the high-pressure adsorption isotherms must exhibit a maximum even by elementary considerations. 


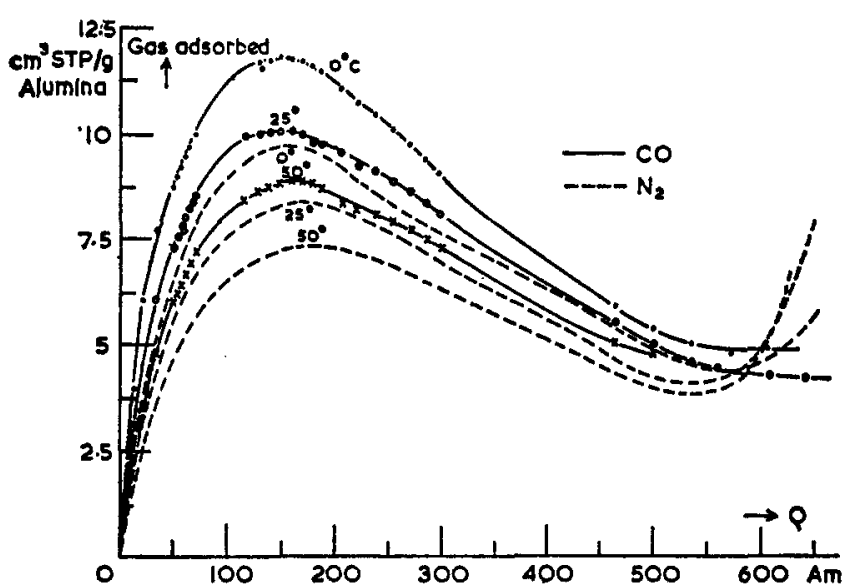

Figure 4.-Adsorption of $\mathrm{CO}$ and $\mathrm{N}_{2}$ on alumina at high gas densities (pressures up to $3000 \mathrm{~atm}$ ). Densities are in amagat units (data of Menon ${ }^{32}$ ).

In this model, the adsorbed molecules are considered to form as if they were a condensed phase of density $\rho_{\mathrm{s}}$ and volume $V_{\mathrm{s}}$. The total amount of adsorbate present in this phase is $g_{\mathrm{a}}=V_{\mathrm{a}} \rho_{\mathrm{a}}$. If there were no adsorption, the amount of gas still present in this phase would have been $V_{\mathrm{a}} \rho_{\mathrm{g}}$. The excess amount measured experimentally is $\Delta g$

$$
\Delta g=V_{\mathrm{a}}\left(\rho_{\mathrm{a}}-\rho_{\mathrm{g}}\right)=g_{\mathrm{a}}-V_{\mathrm{a}} \rho_{\mathrm{g}}
$$

Hence if a surface saturation were reached at high pressures so that $\rho_{\mathrm{a}}$ and hence also $g_{\mathrm{a}}$ became constant, a plot of $\Delta g v s . \rho_{\mathbf{g}}$ should give a straight line with slope $-V_{\mathrm{a}}$, the intercept with the $\Delta g$ axis giving $g_{\mathrm{a}}$ and that with the $\rho_{\mathrm{g}}$ axis, $\rho_{\mathrm{a}}$. Discussions of experimental results on this basis have been given for sorption of $\mathrm{CH}_{4}$ on coal at high pressures. ${ }^{18,26}$ For adsorption of $\mathrm{N}_{2}$ and $\mathrm{CO}$ on alumina also, a straight-line section with downward slope does indeed occur in all isotherms in the density region 200-350 amagats (see Figures 3 and 4).

The linear part (after the maximum) of the adsorption isotherms of $\mathrm{N}_{2}$ and $\mathrm{CO}$ on alumina $a^{30,32}$ have been examined by fitting onto them straight lines by means of the method of least squares. The method as applied also gives an indication of the uncertainties in the values of $g_{\mathrm{a}}$ and $V_{\mathrm{a}}$ thus obtained. This straight-line fitting is carried out by taking different sets of experimental points and plotting the values of $g_{\mathrm{a}}$ and $V_{\mathrm{a}}$ and their uncertainties for these several cases as per the method described by Michels, Abels, ten Seldam, and de Graaff. ${ }^{63}$ The resulting $\rho_{\mathrm{a}}$ 's and their uncertainties are determined in a similar way by fitting the straight lines through $\rho_{\mathrm{g}} v s . \Delta g$, instead of $\Delta g v s . \rho_{\mathbf{g}}$. The difference between these two procedures is that in the $\Delta g v s . \rho_{\mathrm{g}}$ fitting all experimental error is ascribed to the $\Delta g$ values, whereas in the reverse process the $\rho_{\mathrm{g}}$ 's are made responsible. These computations were carried out on an electronic computer. The final results of $g_{\mathrm{a}}, V_{\mathrm{a}}$, and $\rho_{\mathrm{a}}$ are given in Table II. ${ }^{64}$

\section{TABLE II}

Parameters of the Straight Sections in the High-Pressure Adsorption Isotherms of $\mathrm{N}_{2}$ and $\mathrm{CO}$ on Alumina ${ }^{a}$

\begin{tabular}{rrrr} 
Temp, ${ }^{\circ} \mathrm{C}$ & $\sigma_{\mathrm{a}}$ & $V_{\mathrm{a}}$ & $\rho_{\mathrm{a}}$ \\
& \multicolumn{4}{c}{$\mathrm{N}_{2}$ on Alumina } \\
-0.758 & $12.44 \pm 0.16$ & $0.01605 \pm 0.00060$ & $773 \pm 20$ \\
25.085 & $11.07 \pm 0.20$ & $0.01375 \pm 0.00075$ & $803 \pm 30$ \\
49.945 & $9.56 \pm 0.27$ & $0.01075 \pm 0.00090$ & $880 \pm 56$ \\
74.901 & $8.30 \pm 0.10$ & $0.00745 \pm 0.00040$ & $1108 \pm 48$ \\
99.713 & $7.34 \pm 0.29$ & $0.00590 \pm 0.00110$ & $1220 \pm 150$
\end{tabular}

Density of liquid $\mathrm{N}_{2}$ at -196

Density of solid $\mathrm{N}_{2}$

648

824

$$
\text { CO on Alumina }
$$

$-0.769 \quad 15.59 \pm 0.22 \quad 0.02175 \pm 0.00090 \quad 715 \pm 19$

$24.996 \quad 12.78 \pm 0.28 \quad 0.01560 \pm 0.00100 \quad 811 \pm 38$

$49.94510 .71 \pm 0.26 \quad 0.01140 \pm 0.00100 \quad 921 \pm 58$

Density of liquid CO at $-191.5^{\circ} \quad 637$

Density of solid $\mathrm{CO}^{b}$

${ }^{a} g_{\mathrm{a}}$ in $\mathrm{cm}^{3}$ (STP)/g of alumina, $V_{\mathrm{a}}$ in $\mathrm{cm}^{3} / \mathrm{g}$ of alumina, $\rho_{\mathrm{a}}$ in amagats. ${ }^{b} \mathrm{~K}$. Clusius, U. Piesbergen, and $\mathrm{E}$. Varde, Helv. Chim. Acta, 43, 2059 (1960).

The order of magnitude of $\rho_{\mathrm{a}}$ found is that of liquid or solid density of the adsorbate, but the values of $\rho_{\mathrm{a}}$ increase with temperature and exceed even the solid density. This is very improbable. Thus the simple two-phase model seems to fail. This is also to be inferred from the fact that, contrary to predictions from this model, the high-pressure adsorption isotherms do not reach the density axis where $\rho_{\mathrm{g}}$ and $\rho_{\mathrm{a}}$ must be equal. Instead, the CO isotherms level off in the 450640-amagat range (pressure range $800-3000$ atm), whereas the $\mathrm{N}_{2}$ isotherms intersect one another and then take up a rather steeply ascending course with a complete reversal of the temperature dependence of adsorption (see Figures 3 and 4 ).

\section{ENTROPY AND MOBILITY OF MOLECULES ADSORBED}

In the literature of adsorption, the phenomena occurring in unimolecular layers on solid surfaces are often treated as cases either of site, localized, or immobile adsorption, or of mobile, nonlocalized adsorption. Depending on the structure of the surface, the properties of the adsorbed molecules, and the temperature, the actual state of affairs can be anything between these two extremes, or it may even be beyond these extremes. From entropy change calculations, based on experimental adsorption isotherms, inferences can be drawn concerning the mobility of adsorbed 
molecules on the surface..$^{65-68}$ The details of such calculations and their applications for different types of adsorbent-adsorbate systems have been given by de Boer and Kruyer. ${ }^{67,68}$

\section{1. $\mathrm{N}_{2}$ and $\mathrm{CO}$ on Alumina ${ }^{69}$}

Adsorption of $\mathrm{N}_{2}$ and $\mathrm{CO}$ on alumina at about room temperature and at high pressures seems to involve only the loss of one degree of translational freedom for the adsorbed molecules. The molecules retain full freedom for two-dimensional translations and even for vibrations in the third direction perpendicular to the surface ("supermobile"65). At high surface coverages (above $\theta=0.6$ ), the molecules are no longer supermobile; it seems that even translations are being slowly restricted because of the increasing proximity of gas molecules in the mobile layer on the surface.

\section{2. $\mathrm{N}_{2}$ and Ar on Active Carbon ${ }^{70}$}

Entropy changes have been calculated for the adsorption of $\mathrm{N}_{2}$ and $\mathrm{Ar}$ on active carbon at high pressures, measured at $-78,-25,0$, and $20^{\circ}$ by von Antropoff. ${ }^{17}$ The results indicate that both the adsorbed gases behave as mobile two-dimensional layers with restricted freedom for translational movements. At surface coverage values above 0.13 , the adsorbed $\mathrm{N}_{2}$ molecules undergo greater entropy loss than the Ar molecules at same surface coverage, suggesting new restrictions on the rotational freedom of the former. The onset of lateral interactions and the consequent restricted mobility at such low surface coverages are explained as due to the overcrowding of adsorbed molecules on the relatively more active parts of the surface rather than being distributed uniformly on the entire surface. Adsorption above the critical temperature of the adsorbate is indeed believed to take place on the heterogenous parts of the surface (cf. Brunauer ${ }^{7}$.

\section{DECREASE IN DEAD SPACE DUE TO THE VOLUME OF ADSORBED. MOLECULES}

In high-pressure adsorption measurements, the quantity of gas adsorbed, $\Delta g^{\prime}$, is calculated on the basis of the originally determined dead space or free volume, $v$, in the apparatus. When some gas molecules are adsorbed on the adsorbent surface, a small volume corresponding to the real volume of these molecules

(65) C. Kemball, Advan. Catalysis, 2, 233 (1950).

(66) J. H. de Boer, "The Dynamical Character of Adsorption," Oxford University Press, London, 1953, Chapter VI.

(67) J. H. de Boer and S. Kruyer, Koninkl. Ned. Akad. Wetenschap., Proc., B55, 451 (1952); B56, 67, 236, 415 (1953); B57, 92 (1954); B58, 61 (1955).

(68) S. Kruyer, Thesis, Delft, 1955.

(69) J. H. de Boer and P. G. Menon, Koninkl. Ned. Akad. Wetenschap., Proc., B65, 17 (1962).

(70) P. G. Menon and P. Ramamurthy, Kolloid-Z. Z. Polymere, 206, 159 (1965). becomes inaccessible to the free gas molecules. The kinetic movements of the free molecules alone are responsible for the observed pressure. Hence the gas density $\rho$, calculated from this pressure (using the experimental data for the compressibility of the adsorbate gas and hence not requiring any additional correction for the dimensions of the molecules in the gas phase), is strictly valid only for the residual volume or available free space after adsorption at this gas density. If the total amount of gas initially taken in the adsorption apparatus is $g$, the $\Delta g^{\prime}$ values are calculated from

$$
\Delta g^{\prime}=g-\rho v
$$

where $v$ is the total free volume of the gas phase when there is no adsorption. The real free volume, $v^{\prime}$, when $\Delta g^{\prime \prime}\left(\mathrm{cm}^{3}\right.$ (STP)/g of adsorbent) is already adsorbed, will be

$$
v^{\prime}=v-\Delta g^{\prime \prime} v_{\mathrm{s}} w
$$

where $v_{\mathrm{B}}$ is the real volume of the molecules in $1 \mathrm{~cm}^{3}$ (STP) of the gas when they are in the adsorbed state on the surface, and $w$ is the weight in grams of the adsorbent in the apparatus. The real adsorbed amount $\Delta g^{\prime \prime}$ can now be calculated.

$$
\begin{aligned}
w \Delta g^{\prime \prime}=g-\rho\left(v-\Delta g^{\prime \prime} v_{\mathrm{a}} w\right) & = \\
& \frac{g-\rho v}{1-\rho v_{\mathrm{a}}}=\frac{\Delta g^{\prime}}{1-\rho v_{\mathrm{s}}}
\end{aligned}
$$

Since $\Delta g^{\prime}=w \Delta g$

$$
\Delta g^{\prime \prime}=\frac{\Delta g}{1-\rho v_{\mathrm{s}}}
$$

There seems to be no direct method for determining accurately the specific volume $v_{s}$ (finite volume of molecules) of the gas in the adsorbed state. As an approximation, three different values for $v_{\mathrm{s}}$ may be considered based on (1) the van der Waals constant $b$ for the gas; (2) the assumption that the adsorbed gas has the same density as that of the liquefied gas at its boiling point; and (3) the assumption that the adsorbate density is equal to the density of the solidified gas. In the early part of the high-pressure adsorption isotherm, the choice of the adsorbate density based on assumption 1 is to be preferred since the adsorbed gas in this pressure region behaves fairly well as a mobile two-dimensional gas (see section IV.C.1), but at high pressures or densities (say, beyond the maximum in the experimental isotherms) the assumption of liquid density or solid density might perhaps be a better choice. As a typical case, the adsorption of $\mathrm{N}_{2}$ on alumina at high pressure ${ }^{30}$ at $25^{\circ}$ has been recalculated after applying a correction to account for the decrease in dead space with increasing adsorp- 
tion using the three possible values for $v_{\mathrm{s}}$ mentioned above. The results are shown in Figure 5 . The $v_{\mathrm{m}}$ value for nitrogen from a BET plot of the isotherm at $-195^{\circ}$ on the same adsorbent and the liquid and solid density values for nitrogen are also indicated in the figure.

The assumption of liquid or solid density for the adsorbed gas leads to a steep increase in adsorption reminiscent of condensation phenomena on approaching the saturation vapor pressure below the critical temperature of the gas. This is very improbable at about $170^{\circ}$ above the critical temperature of nitrogen. Hence the adsorbed gas has to be credited with a density even higher than that of the solidified gas to avoid this condensation-type behavior of the isotherm. The analysis of the linear descending part of $\mathrm{N}_{2}$ and $\mathrm{CO}$ adsorption isotherms (see Table II) also suggests that the density of the adsorbed phase is of the same order as, or higher than, the solid density of the adsorbate. This may, perhaps, be only an indication that the simple two-phase model is too inadequate to represent the actual situation on the surface.

\section{E. ABSOLUTE ADSORPTION}

Absolute adsorption $g_{\mathrm{a}}$ may be defined as the total amount of gas in a one-molecule-thick layer (surface layer) on the entire surface of the adsorbent, i.e., the sum of the experimentally measured excess adsorption or "differential adsorption" $(\Delta g)$ and the gas in the surface layer owing to the applied gas density ( $\rho)$ only

$$
g_{\mathrm{a}}=\Delta g+\rho S d
$$

where $d$ is the thickness or height of the adsorption layer on the surface, and $S$ is the surface area of the adsorbent.

By analogy to the discussion in the last section, the real volume of the surface layer when $\Delta g^{\prime \prime}\left(\mathrm{cm}^{3}\right.$ (STP)) of gas is already adsorbed will be not $S d$, but $S d-\Delta g^{\prime \prime} v_{s e}$. Hence absolute adsorption after this volume correction $\left(g_{\mathbf{a}}{ }^{\prime}\right)$ will be

$$
g_{\mathrm{a}}{ }^{\prime}=\Delta g^{\prime \prime}+\rho\left(S d-\Delta g^{\prime \prime} v_{\mathrm{s}}\right)
$$

Substituting eq 7 into eq 9

$$
g_{\mathrm{s}}{ }^{\prime}=\frac{\Delta g}{1-\rho v_{\mathrm{s}}}+\rho\left(\left(S d-\frac{\Delta g}{1-\rho v_{\mathrm{s}}} v_{\mathrm{s}}\right)=\Delta g+\rho S d\right.
$$

which is eq 8 . Hence

$$
g_{\mathrm{a}}{ }^{\prime}=g_{\mathrm{a}}
$$

The absolute adsorption thus remains unaltered; unlike the differential adsorption (Figure 5), it is independent of the value assumed for the density of the adsorbed phase. Hence absolute adsorption is not a mere hypothetical concept; it seems to be a fair repre-

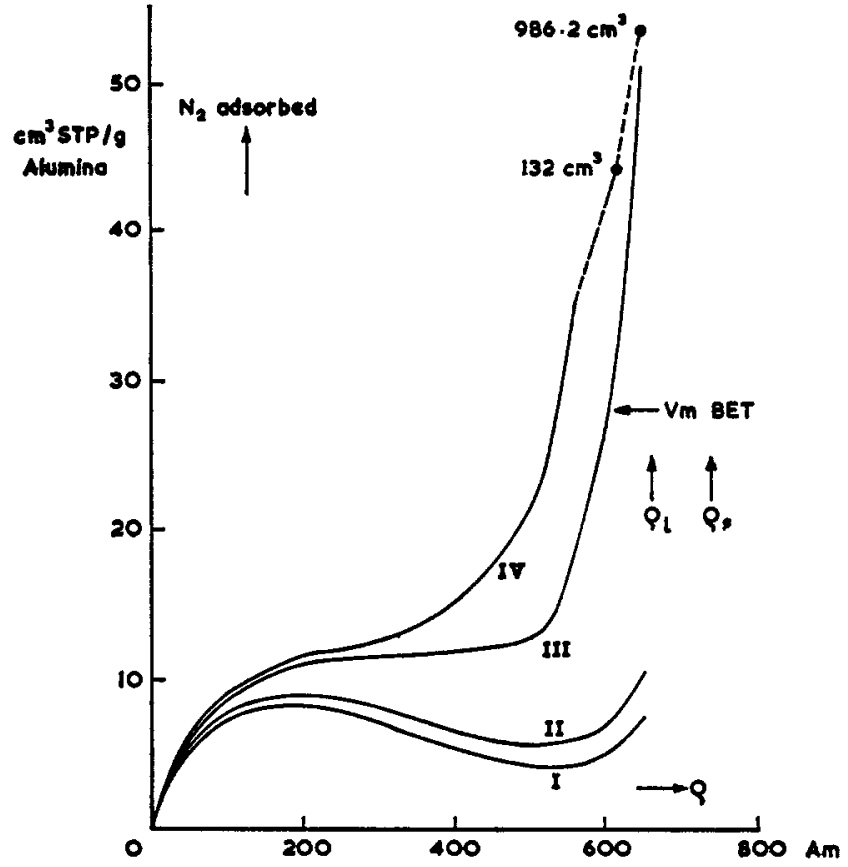

Figure 5.-Correction for the finite volume of adsorbed molecules. Curve $I$ is the $\Delta g v s$. $\rho$ plot for $\mathrm{N}_{2}$ on alumina at $25^{\circ}$ : application of this correction basing specific volume of adsorbed gas on van der Waals constant $b$ (II), on solid density (III), or on liquid density (IV) of $\mathrm{N}_{2}$ (data of Menon ${ }^{31}$ ).

sentation of the actual situation in the surface layer or sphere of influence of the adsorbent.

However, the value of $d$, the thickness of the adsorbed layer, has to be chosen on a more or less arbitrary basis. For a discussion of $\mathrm{N}_{2}$ and $\mathrm{CO}$ adsorption isotherms on alumina, the van der Waals diameter has been chosen $\left(d=3.15 \AA\right.$ for $\mathrm{N}_{2}$ and $3.17 \AA$ for $\left.\mathrm{CO}\right)$. The choice of any other value for $d$ based on LennardJones model or that derived from second virial coefficient for the gas will also be equally empirical and arbitrary for adsorption studies, because of the reasons given in sections III.C and D.

The discussion in sections IV.D and E so far is based on $g$, the amount of gas adsorbed per gram adsorbent, as derived from the measured gas pressure and the dead-space value without steric corrections. It is obvious, however, that the new correction discussed here (section IV.D) is to be applied only after the steric corrections for helium and the adsorbate molecule (see sections III.C and D) have been applied to the deadspace value. In Figure 6 the differential adsorption, $\Delta g$, and the absolute adsorption, $g_{\mathrm{s}}$, both after steric corrections, for $\mathrm{N}_{2}$ on alumina are shown as a function of gas density (pressures up to $3000 \mathrm{~atm}$ ). The density of liquid and solid $\mathrm{N}_{2}$ and $v_{\mathrm{m}}$ value for $\mathrm{N}_{2}$ obtained from a BET plot of the low-pressure $-196^{\circ}$ isotherm on the alumina are also indicated in the figure.

In the gas density range of 550-640 amagats, the $g_{\mathrm{a}}$ values exceed the $v_{\mathrm{m}}$ value of $27.8 \mathrm{~cm}^{3}(\mathrm{STP}) / \mathrm{g}$. It has to be remembered here that the $v_{\mathrm{m}}$ value is 


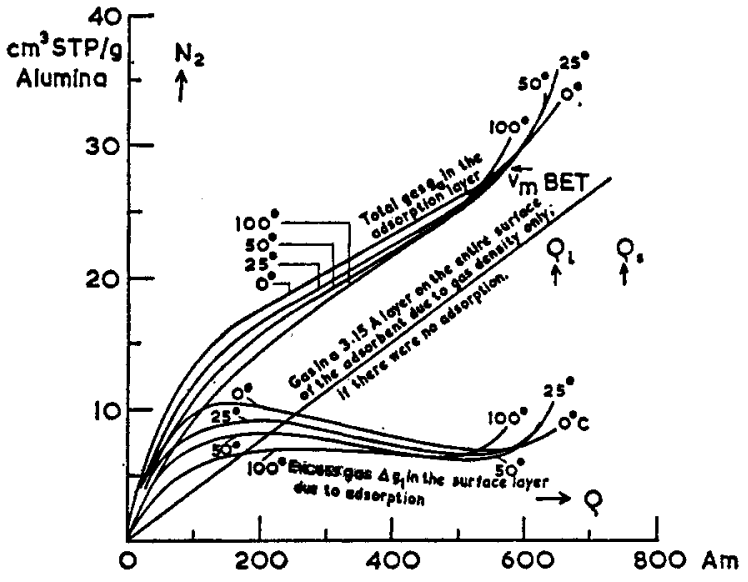

Figure 6.-Differential adsorption $\Delta g_{1}$ and absolute adsorption $g_{\mathrm{a}}$ of $\mathrm{N}_{2}$ on alumina at high gas densities (data of Menon ${ }^{31}$ ).

determined from adsorption at $-196^{\circ}$; at higher temperatures, especially above the critical temperature, the use of this value to denote complete unimolecular surface coverage may be questionable. At the closest contact attained at infinitely high pressures, a nitrogen molecule will have a diameter of about $3.15 \AA$ and a surface area of $8.57 \AA^{2}$ instead of $4.34 \AA$ and 16.2 $\AA^{2}$, respectively, used in the BET method. Hence, above the critical temperature, the maximum limit of unimolecular coverage of the alumina surface with $\mathrm{N}_{2}$ molecules may perhaps be attained only on adsorption of $27.8 \times 16.2 / 8.57=52.8 \mathrm{~cm}^{3}(\mathrm{STP}) / \mathrm{g}$ of alumina. This is not reached in the high-pressure adsorption measurements; even at about $3000 \mathrm{~atm}$, the highest $g_{\mathrm{a}}$ value reached is only $34.6 \mathrm{~cm}^{3}$ (STP)/g of alumina. For purposes of comparison of isotherms at different temperatures, however, the BET $v_{\mathrm{m}}$ value is still preferred since it is a quantity derived from experimental data.

\section{F. SURFACE COVERAGE AT HIGH GAS DENSITIES}

At the density where the differential adsorption $(\Delta g)$ isotherms show a maximum, the $g_{\mathrm{a}}$ values in the absolute adsorption isotherms at different temperatures are nearly constant (apparent surface saturation) and equal to about $60 \%$ of the $v_{\mathrm{m}}$ value (from a BET plot). Entropy calculations (section IV.C.1) show that up to a surface coverage of about $64 \%$ both nitrogen and carbon monoxide adsorbed on alumina behave as mobile two-dimensional gases exhibiting even some freedom for vibrations perpendicular to the surface (supermobile). At coverages above $64 \%$ the supermobility is lost and the first signs of restrictions on the two-dimensional translations (and perhaps rotations also) are seen from the increasing entropy loss on adsorption. This indicates that the "apparent surface saturation" is the upper limit at which the adsorbed molecules still behave as a two-dimensional gas on the surface. Accommodating more molecules in the surface layer is possible only at the expense of the freedom of translation and/or rotation of the already adsorbed molecules.

This overcrowding is of course necessitated by the gas density increasing even after reaching the "apparent surface saturation." Owing to compression only and not to adsorptive forces, more and more gas molecules are brought into the surface layer until some sort of a "complete surface coverage" is reached; this stage is indicated by the minimum in the $\mathrm{N}_{2}$ isotherms (Figure 3) and the leveling off in the CO isotherms (Figure 4) in the 450-550-amagat range. The $g_{\mathrm{s}}$ values in this region are of the same order of magnitude (see Figure 6) as of $v_{\mathrm{m}}$ from a BET plot of the $-195^{\circ}$ nitrogen isotherms. It must be emphasized here that $v_{\mathrm{m}}$ conforms to a unimolecular liquid whereas these $g_{\mathrm{a}}$ values, being so far above the critical temperatures of the adsorbate, are to be considered as an adsorbed unimolecular "gas" layer.

\section{G. POSSIBLE REORIENTATION OF ADSORBED MOLECULES AT HIGH DENSITIES}

Only a tentative explanation has been given ${ }^{31}$ for the second ascending and apparently endothermic part of the $\mathrm{N}_{2}$ adsorption isotherm in the 550-640-amagat range. There are several facts ${ }^{30}$ to show that this new phenomenon in the case of $\mathrm{N}_{2}$ cannot be due to any change undergone by the adsorbent alumina; an explanation for it has to be sought in the adsorbed phase itself. Multimolecular adsorption at so far above the critical temperature of the adsorbate is very unlikely. With a "complete surface coverage" being reached at 450 550 amagats, a further increase in gas density may be forcing the adsorbed $\mathrm{N}_{2}$ molecules to reorient themselves from the freely rotating position to the erect or perpendicular position on the surface. This is a more compact packing on the surface than when the molecules are rotating. The loss of rotational entropy due to the orderly lining-up of the molecules may be compensated by the freedom to move on the extra surface created by the more compact packing; in addition, the erect molecules have probably more freedom to oscillate or vibrate in directions perpendicular to their own axis. The result of all these can be a net gain in entropy on erection. ${ }^{71}$ The situation may be analogous to the well-known case of adsorption of stearic acid or similar compounds on water surface ${ }^{72}$ or to the adsorption of lauric acid on alumina. ${ }^{73}$ The endothermic nature of the second ascending part of the $\mathrm{N}_{2}$ adsorption isotherms may be due to the greater mobility of the adsorbed molecules at higher temperatures rendering the reorientation easier.

(71) J. H. de Boer, ref 66, Chapter VII.

(72) Cf. R. B. Dean, "Modem Colloids," D. Van Nostrand Co., New York, N. Y., 1948, p 54.

(73) B. C. Lippens, Doctorate Thesis, Technological University, Delft, 1961. 
The high-pressure adsorption isotherms of $\mathrm{CO}$ on alumina at 0 and $25^{\circ}$ do not exhibit the second ascending part seen for $\mathrm{N}_{2}$ isotherms in the density range of 550-640 amagats. Adsorbed CO molecules may have a relatively greater resistance to reorientation because of their higher heat of adsorption, ${ }^{32}$ the larger induced dipole moment in $\mathrm{CO}$ on adsorption, ${ }^{69}$ and, perhaps, a possible mutual alignment of the permanent dipoles of $\mathrm{CO}$ in a flat position at high surface coverages. At higher temperatures this resistance can perhaps be overcome and the $\mathrm{CO}$ adsorption isotherms also may intersect one another and rise again steeply just as in the case of the $\mathrm{N}_{2}$ isotherms. This is yet to be tested experimentally.

\section{Other Results from High-Pressure Adsorption Studies}

\section{A. SORPTION OF METHANE ON COAL}

The earliest attempts in the field of high-pressure adsorption were to measure the sorption of methane by coal with a view of getting a better insight into the mechanism of methane hold-up in coal and the release of this methane when seams of coal were exposed during mining; sometimes leading to disastrous fires and explosions in coal mines. In recent years, Palvelev ${ }^{74}$ and Khodot ${ }^{75}$ have obtained methane sorption isotherms for Russian coals up to $1000 \mathrm{~atm}$. The apparent sorption they found either increases only slightly with pressure above $200 \mathrm{~atm}$, or declines from a maximum near this pressure to a limiting value which is well above zero at $1000 \mathrm{~atm}$. The maximum in methane sorption on coal has also been observed in an accurate study ${ }^{26}$ up to $500 \mathrm{~atm}$ and in a more extensive study ${ }^{18}$ up to $1000 \mathrm{~atm}$. The isotherm actually levels off to a saturation value if the amount adsorbed, measured experimentally, is corrected for the increasing density of the gas phase ${ }^{26}$ ( $c f$. section IV.B). The general conclusion is that methane is physically adsorbed on the large internal surface of coal and is not chemisorbed or held in the type of solid solution formed by compressed gases in rubber and linear high polymers. The adsorbed amount at $1000 \mathrm{~atm}$ is higher than what is to be expected. This may be due to the compressibility of coal increasing the pore volume at high pressure and hence changing the dead space in the apparatus. A more probable cause is the penetration of methane molecules at high pressures into spaces between the coal lamellae which are not included in the dead-space determination with helium at 1 atm (see last paragraph of section III.B).

(74) V. T. Palvelev, Dokl. Akad. Nauk SSSR, 62, 779 (1948); Chem. Abstr., 43, 1237 (1949).

(75) V. V. Khodot, Izv. Akad. Nauk SSSR, Otd. Tekh. Nauk, 733 (1948); 991 (1949); 1085 (1951).

\section{B. HIGH-PRESSURE ADSORPTION DATA FOR HYDROCARBONS}

Ray and $\mathrm{Box}^{76}$ have measured the adsorption of $\mathrm{H}_{2}, \mathrm{CO}, \mathrm{CO}_{2}, \mathrm{CH}_{4}, \mathrm{C}_{2} \mathrm{H}_{2}, \mathrm{C}_{2} \mathrm{H}_{4}, \mathrm{C}_{2} \mathrm{H}_{6}, \mathrm{C}_{3} \mathrm{H}_{6}, \mathrm{C}_{3} \mathrm{H}_{8}$, and $n-\mathrm{C}_{4} \mathrm{H}_{10}$ on a single sample of coconut shell charcoal at $100-450^{\circ}$ in the pressure range $0-14$ atm. Adsorption equilibrium data for $\mathrm{C}_{1}$ to $\mathrm{C}_{4}$ hydrocarbons and their binary mixtures on silica gel and several types of activated carbon up to 20 atm have been published; several correlations to predict adsorption equilibria have also been studied..$^{77}$

The adsorption isotherms for $\mathrm{N}_{2}$ and $\mathrm{CH}_{4}$ and their binary mixtures on molecular sieves have been studied at $-150,-98,-78$, and $+20^{\circ}$ up to $80 \mathrm{~atm}^{78} \mathrm{~A}$ mass spectrometer has been used to analyze the samples of the mixture drawn from the apparatus at equilibrium. The adsorption of $\mathrm{CH}_{4}$ approaches a maximum of about $5 \mathrm{mmol}$, corresponding to $95 \%$ of a monolayer.

The potentialities of fractional separation of hydrocarbons by selective adsorption at high pressures seem to be very high in the processing of petroleum and natural gases. This has led to several new investigations in this field during the last 5 years. The suitability of various isotherm equations for describing the adsorption equilibria of individual gases has been discussed by Szepesy, Illes, and Benedek, ${ }^{79}$ but only their limited data ${ }^{80}$ up to a pressure of 7 atm have been examined. The work of Gilmer and Kobayashi ${ }^{34,35}$ and of Mason and Cooke ${ }^{36}$ have already been mentioned in section II.F. Martin ${ }^{81}$ has developed a cyclic adsorption process for fractionating mixtures by selective adsorption. In this procedure the pressure is cycled and the effluents (high-pressure and low-pressure streams from the adsorbent bed) are recycled in part to increase efficiency. An improvement is made by compressing some of the low-pressure effluent and recycling it to the high-pressure adsorption chamber.

The adsorption of $\mathrm{C}_{2}-\mathrm{C}_{5}$ hydrocarbons from natural gas (containing $\mathrm{CH}_{4}(93.8), \mathrm{C}_{2} \mathrm{H}_{6}(4.0), \mathrm{C}_{3} \mathrm{H}_{8}$ (1.6), $n-\mathrm{C}_{4} \mathrm{H}_{10}(0.3), i-\mathrm{C}_{4} \mathrm{H}_{10}(0.2), n-\mathrm{C}_{5} \mathrm{H}_{12}(0.06)$, and $i-\mathrm{C}_{5} \mathrm{H}_{12}$ $(0.04$ vol $\%)$ has been studied ${ }^{82}$ on charcoal, $\mathrm{CaX}$ zeolite, and silica gel at $20^{\circ}$ up to $50 \mathrm{~atm}$, at an inlet velocity of $0.12 \mathrm{~m}^{3} /\left(\mathrm{cm}^{2} \mathrm{sec}\right)$. Hydrocarbon concentrations in the exit gas vs. gas consumption curves are obtained in this way for each hydrocarbon at various

(76) G. C. Ray and E. O. Box, Ind. Eng. Chem., 42, 1315 (1950).

77) W. K. Lewis, E. R. Gilliland, B. Chertow, and W. P. Cadogen, ibid., 42, 1319 (1950).

(78) P. B. Lederman and B. Williams, A.I.Ch.E. J., 10, 30 (1964).

(79) L. Szepesy, V. Illes, and P. Benedek, Acta Chim. Acad. Sci. Hung., 35, 433 (1963); Chem. Abstr., 59, 51 (1963).

(80) L. Szepesy and V. Illes, Acta Chim. Acad. Sci. Hung., 35, 37 (1963); Chem. Abstr., 59, 1120 (1963).

(81) H. Z. Martin, U. S. Patent 3,149,934 (Sept 22, 1964); Chem. Abstr., 61, 12969 (1964).

(82) A. M. Rasulov and V. S. Velikovskii, Gaz. Prom., 10, 45 (1965); Chem. Abstr., 62, 9831 (1965). 
pressures. Relative dynamic adsorptive activity (RDAA) and adsorption time are determined for each adsorbent from these curves. At both low and high pressures the RDAA's of the charcoal and the zeolite are higher than that of the silica gel. While the RDAA of silica gel increases with increasing pressure faster than that of the other two adsorbents, its absolute value is lower. The charcoal and the zeolite are recommended as most effective adsorbents for shortcycle hydrocarbon extracting columns.

Studies of adsorption rates have been made ${ }^{83}$ in an experimental unit designed so that conditions existing in the treatment of high-pressure natural gas mixtures could be duplicated. It is concluded that experimentally determined break-out curves are useful for investigating the effects of different process variables on the rate of adsorption and the efficiency of operations of fixed-bed adsorption columns. Over the ranges of variables studied, pressure, temperature, and gas concentration have little effect upon the rate of saturation of the adsorbent particles. Beyond a certain minimum column length the length of the mass-transfer zone is stabilized. Decreasing particle size and increasing flow rate tend to increase the rate of saturation of the adsorbent. A simplified mathematical model, together with a correlation for a parameter describing the absolute rate of adsorption, is shown to be useful for describing the fixed-bed adsorption process.

\section{PURIFICATION AND SEPARATION OF GASES}

High-pressure adsorption seems to be a promising method for purification and separation of gases. From a study ${ }^{84}$ of the isotherms of $\mathrm{CH}_{4}, \mathrm{CO}, \mathrm{N}_{2}$, and binary mixtures of these with $\mathrm{H}_{2}$ on active carbon at $20^{\circ}$ and pressures up to $100 \mathrm{~atm}$, it is found that the presence of $\mathrm{H}_{2}$ decreases the adsorption capacity of the other gases. The coefficients of the separating capacity of the carbon, which determine the composition of the adsorbed phase in relation to that of the gaseous phase, for six binary and a few multicomponent mixtures have been determined. This study has led to a purification method $^{85}$ for $\mathrm{H}_{2}$ in which a moving bed of activated carbon yields $\mathrm{H}_{2}$ of purity $99.9 \%$ or better. From binary, ternary, and quaternary mixtures of $\mathrm{H}_{2}$ with $\mathrm{CH}_{4}, \mathrm{CO}$, and $\mathrm{N}_{2}$, at pressures of 5-25 atm, $100 \%$ purification of $\mathrm{H}_{2}$ is obtained at high bed velocities. Optimum conditions of operation are $25 \mathrm{~atm}$, highest quality of active carbon, bed length less than $70 \mathrm{~cm}$, bed velocity of $10-80 \mathrm{~g} / \mathrm{min}$, and temperature of de-

(83) D. E. Marks, R. J. Robinson, C. W. Arnold, and A. E. Hoffmann, J. Petrol. Technol., 15, 443 (1963).

(84) Z. A. Zhukova and N. V. Kel'tsev, Tr. Vses. Nauchn.Issled. Inst. Prirodn. Gazov, [6] 154 (1959); Chem. Abstr., 54, 14633 (1960).

(85) N. V. Kel'tsev and Z. A. Zhukova, Tr. Vses. Nauchn.-Issled. Inst. Prirodn. Gazov, [12] 143 (1961); Chem. Abstr., 57, 12287 (1962).

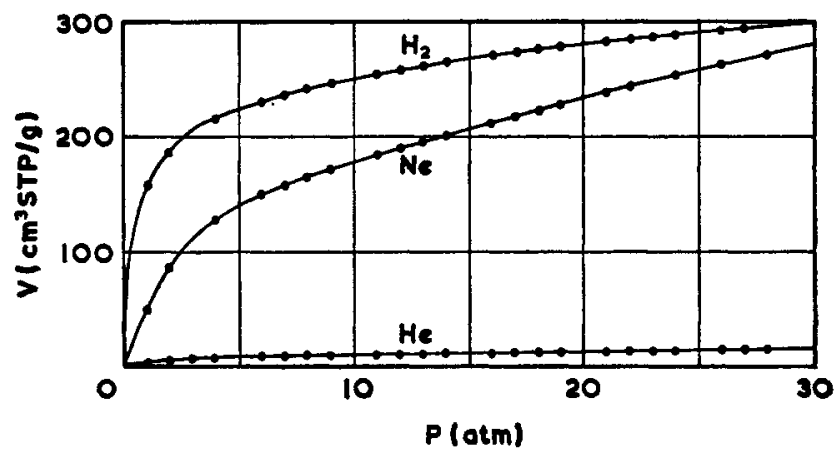

Figure 7.-Adsorption of $\mathrm{He}, \mathrm{Ne}$, and $\mathrm{H}_{2}$ on active carbon at liquid nitrogen temperature (data of Czaplinski and Zielinski ${ }^{19}$ ).

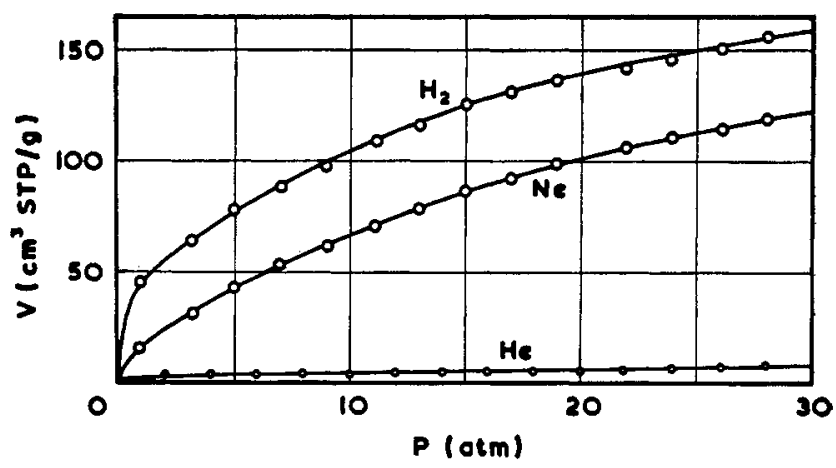

Figure 8.-Adsorption of $\mathrm{He}, \mathrm{Ne}$, and $\mathrm{H}_{2}$ on silica gel at liquid nitrogen temperature (data of Czaplinski and Zielinski20).

sorption zone $200^{\circ}, 10 \%$ of purified $\mathrm{H}_{2}$ being used for desorption.

Simpson and Cummings ${ }^{86}$ have developed an equation for predicting the performance of a solid adsorbent in a dynamic system. As a test case the drying of air on silica gel has been studied at $30-120^{\circ} \mathrm{F}$, gas velocity $10-90 \mathrm{ft} / \mathrm{min}$, pressure $40-280 \mathrm{psi}$, and concentration of moisture in air $10-90 \%$ of the saturation value. It is claimed that an extension of this work can lead to the derivation of equations for other adsorbents and adsorbates.

Based on the results of high-pressure adsorption studies of $\mathrm{He}, \mathrm{Ne}$, and $\mathrm{H}_{2}$ on active carbon ${ }^{19}$ and silica gel and alumina $a^{20}$ at liquid nitrogen temperature (Figures 7-9), Zielinski ${ }^{87}$ developed a process for separation of $\mathrm{He}$ and $\mathrm{Ne}$ from $\mathrm{He}-\mathrm{Ne}$ concentrates, containing $\mathrm{N}_{2}$ and $\mathrm{H}_{2}$. A gas mixture containing $\mathrm{He}$ (16), $\mathrm{Ne}(58), \mathrm{H}_{2}$ (3), and $\mathrm{N}_{2}(23 \%)$ is fed into a charcoal column cooled with liquid $\mathrm{N}_{2}$. When the pressure rises to $1 \mathrm{~atm}, \mathrm{He}$ is discharged slowly. At $3 \mathrm{~atm}$, when the outlet gas composition has changed, the inlet is closed; the column is partially lifted (at the inlet side) from the liquid $\mathrm{N}_{2}$ bath, allowing the desorption of a $\mathrm{He}-\mathrm{Ne}$ mixture. At 5 atm when pure $\mathrm{Ne}$ is desorbed, the

(86) E. A. Simpson and W. P. Cummings, Chem. Eng. Progr., 60, $57(1964)$.

(87) E. Zielinski, Polish Patent 42,225 (Dec 21, 1959); Chem. Abstr., 55, 6803 (1961). 


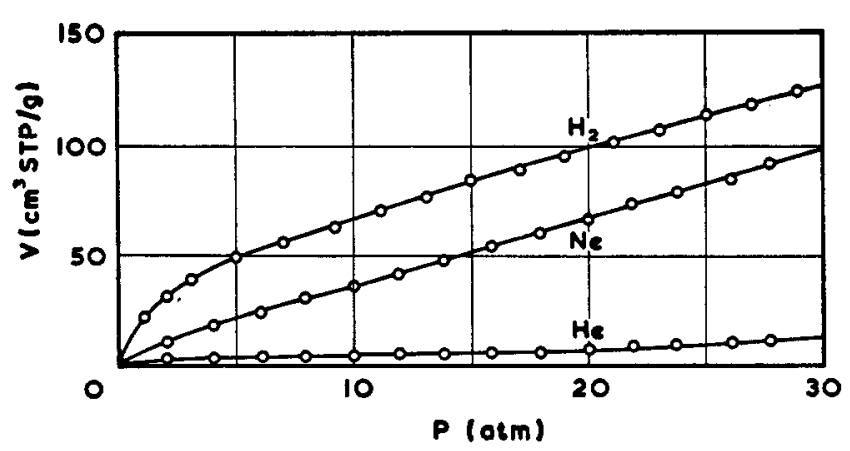

Figure 9.-Adsorption of $\mathrm{He}, \mathrm{Ne}$, and $\mathrm{H}_{2}$ on alumina at liquid nitrogen temperature (data of Czaplinski and Zielinski ${ }^{20}$ ).

desorption is speeded up by warming. Toward the end $\mathrm{H}_{2}$ is desorbed followed by $\mathrm{N}_{2}$. The exit gas composition is continuously followed by thermoconductometric analysis.

\section{CHEMISORPTION DATA AT HIGH PRESSURES}

\section{1. $\mathrm{N}_{2}$ and $\mathrm{H}_{2}$ on Iron Catalysts}

The method adopted by Emmett and Brunauer ${ }^{40}$ for chemisorption study of $\mathrm{N}_{2}$ on a doubly promoted iron catalyst is subject to two fundamental uncertainties (see section II.H), in spite of the pioneering nature of their work. Hence the discussion here is confined to the more recent and reliable measurements of Sastri and Srikant. ${ }^{41,42}$ Adsorption of $\mathrm{N}_{2}$ and $\mathrm{H}_{2}$ separately and from a $3 \mathrm{H}_{2}: 1 \mathrm{~N}_{2}$ mixture has been measured on a commercial synthetic ammonia catalyst at 97,134 , $203,250,300,350$, and $400^{\circ}$ up to $50 \mathrm{~atm}$ (see Figure 10 for $\mathrm{N}_{2}$ ). For characterization of the surface of the catalyst (BET surface area, extent of free iron on the surface, and alkali coverage of the surface), low-temperature adsorption of $\mathrm{N}_{2}, \mathrm{CO}$, and $\mathrm{CO}_{2}$ has also been carried out. The amounts of $\mathrm{N}_{2}$ and $\mathrm{H}_{2}$ adsorbed at higher pressures and temperatures are considerably in excess of the maximum possible surface accommodation. It is suggested that the chemisorbed $\mathrm{N}$ and $\mathrm{H}$ atoms penetrate interstitially into the metal lattice. There is considerable hysteresis in the adsorption-desorption runs at all the temperatures, as is usual in chemisorption. The amount of gas retained by the catalyst is found to depend on the maximum values of adsorption attained. Where the latter are low $\left(\mathrm{H}_{2}\right.$ at $134^{\circ}, \mathrm{N}_{2}$ at 97 and $134^{\circ}$ ), most of the gas taken up is given off readily on lowering the pressure. At higher temperatures (e.g., at $203^{\circ}$ for both gases) the amount of gas adsorbed is large and only a small part of it is desorbed on lowering the pressure. Since the amounts of either gas taken up at higher pressures and temperatures are much higher than the maximum possible surface saturation values, this large hysteresis is attributed to the difficulty of the gas in the metal lattice in coming out. If the surface happens to be completely saturated with chemisorbed $\mathrm{N}$ and $\mathrm{H}$ atoms, or if such free atoms are

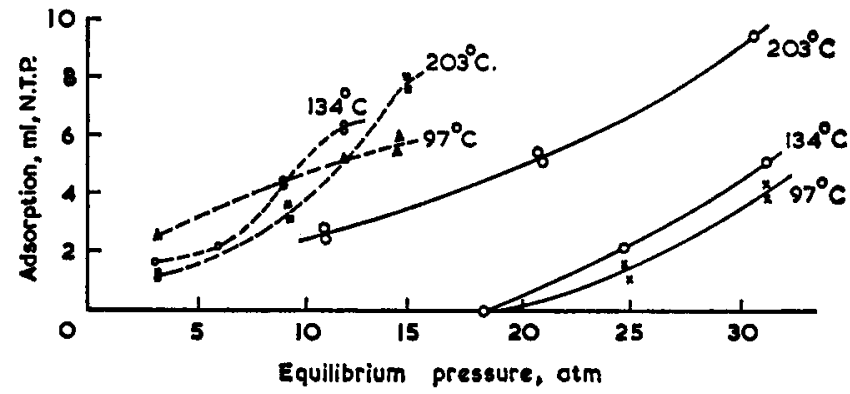

Figure 10.-Chemisorption of $\mathrm{N}_{2}$ from pure gas (-) and from a $3 \mathrm{H}_{2}: 1 \mathrm{~N}_{2}$ mixture (-- ) on iron catalyst at high pressures (data of Sastri and Srikant ${ }^{\star 1}$ ).

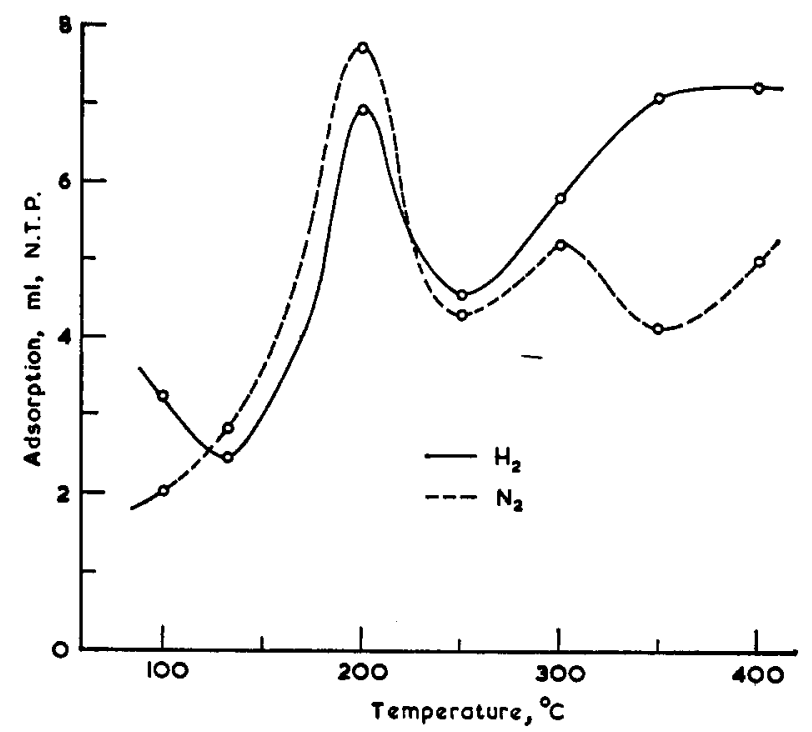

Figure 11.-Adsorption isobars of $\mathrm{H}_{2}$ and $\mathrm{N}_{2}$ on iron catalyst at high pressures (data of Sastri and Srikant ${ }^{41}$ ).

isolated singly or available in rather inaccessible locations, the interstitial $\mathrm{N}$ and $\mathrm{H}$ atoms will be entrapped in the lattice structure of the solid for want of vacant sites at the surface to permit their back migration and recombination (into $\mathrm{N}_{2}$ and $\mathrm{H}_{2}$ molecules) at the surface.

The adsorption isobars of $\mathrm{N}_{2}$ and $\mathrm{H}_{2}$ show a pronounced maxima at $200^{\circ}$ (Figure 11). Whether the maximum found for $\mathrm{H}_{2}$ at $200^{\circ}$ corresponds to the latter (type B) of the two maxima found by Emmett and Harkness ${ }^{88}$ at -78 and $100^{\circ}$, or whether it represents a third type of atomic chemisorption, can be decided only by additional measurements in the $0-200^{\circ}$ range at high pressures. The $\mathrm{N}_{2}$ isobar shows two maxima at 200 and $300^{\circ}$ which have not been reported previously.

The results for the adsorption of $\mathrm{N}_{2}$ alone and of $\mathrm{N}_{2}$ from a $3 \mathrm{H}_{2}: 1 \mathrm{~N}_{2}$ mixture are shown in Figure 10. Since the formation of ammonia over this catalyst becomes just noticeable at $250^{\circ}$, mixed adsorption studies were restricted to about $50^{\circ}$ below this tempera-

(88) P. H. Emmett and R. W. Harkness, J. Am. Chem. Soc., 57, 1631 (1935). 


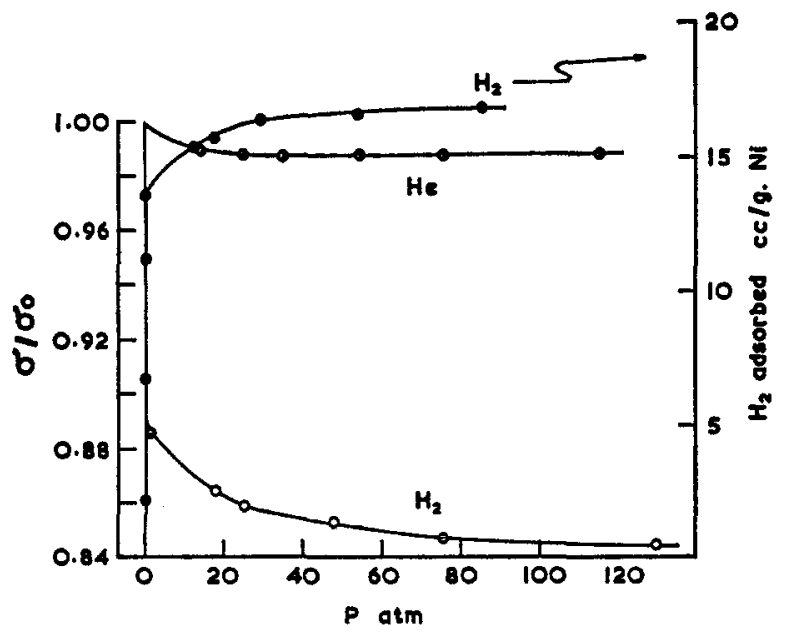

Figure 12.-Magnetization-pressure isotherms for $\mathrm{He}$ and $\mathrm{H}_{2}$ and corrected volume-pressure isotherms (for fast chemisorption only) for $\mathrm{H}_{2}$ on nickel-kieselguhr catalyst at room temperature (data of Vaska and Selwood ${ }^{43}$ ).

ture. The adsorption of $\mathrm{N}_{2}$ is considerably enhanced by the presence of $\mathrm{H}_{2}$. A similar enhancement is also found for $\mathrm{H}_{2}$ chemisorption from the gas mixture: this is well known in low-pressure chemisorption studies on ammonia synthesis catalysts. This mutual enhancement is interpreted in terms of the effects of the individual chemisorption and of the $\mathrm{N}-\mathrm{H}_{x}$ complexes formed between them on the work function barrier.

\section{2. $\mathrm{H}_{2}$ on Nickel}

Some preliminary studies on diffusion and adsorption of $\mathrm{H}_{2}$ in a porous nickel catalyst up to $30 \mathrm{~atm}$ have been carried out by Doerner ${ }^{89}$ who concludes that the adsorption is $50 \%$ complete instantaneously and that the slow adsorption is due to the diffusion in the catalyst micropores. Vaska and Selwood ${ }^{43}$ have undertaken a more detailed study of $\mathrm{H}_{2}$ adsorption on nickelkieselguhr hydrogenation catalyst at elevated pressures and its correlation with the accompanying decrease in magnetization. Their results (Figure 12) show that changes of magnetization occur at least up to $100 \mathrm{~atm}$. A magnetization-pressure isotherm for $\mathrm{He}$ is also given in Figure 12 for comparison. At higher pressures the adsorption of $\mathrm{H}_{2}$ causes a progressive decrease of magnetization of nickel. Partly based on Doerner's data, an attempt has been made to calculate separately (a) fast chemisorption and (b) physical adsorption plus slow sorption from the observed total adsorption data at high pressures. The isotherm of the instantaneous chemisorption thus calculated is also shown in Figure 12.

The results show that the monolayer of chemisorbed $\mathrm{N}_{2}$ on the surface of nickel is not complete at $1 \mathrm{~atm}$, but the saturation is reached at about $100 \mathrm{~atm}$. No direct

(89) W. A. Doerner, Dissertation, University of Michigan, 1952; Chem. Abstr., 47, 8929 (1953). evidence has been found regarding possible penetration of hydrogen into the nickel lattice at high pressures, but indications are that, if any such penetration occurs, it must be an extremely slow process.

\section{Some General Considerations}

\section{A. REPRODUCIBILITY IN ADSORPTION-DESORPTION MEASUREMENTS}

Two types of information can be obtained by checking the reproducibility in adsorption-desorption measurements: (a) the general accuracy of the experimental technique followed and (b) whether the adsorbent undergoes any plastic deformation or permanent set at the highest pressure employed in the measurements. The reversibility of the adsorption and the quickness with which adsorption equilibrium is established, as indicated by steady pressure within $1 \mathrm{hr}$ of changing to a new pressure, can also confirm that no chemisorption or any such slow activated process is involved in the case of the particular adsorbent-adsorbate system under study. Such information has been obtained for the $\mathrm{N}_{2}$-alumina ${ }^{30}$ and $\mathrm{CO}$-alumina $a^{32}$ systems. The pressures, when the mercury is at the platinum contacts of the piezometer, in three representative series of adsorption-desorption measurements for $\mathrm{N}_{2}$ on alumina are given in Table III.

\section{TABLE III}

Reproducibility in Adsorption-Desorption Measurements For Nitrogen on AlUMina ${ }^{a}$

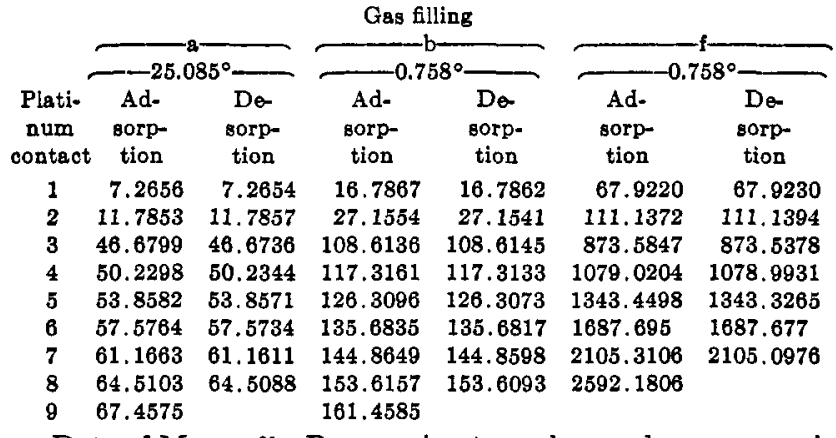

a Data of Menon. ${ }^{31}$ Pressure in atmospheres when mercury is at the various platinum contacts of the piezometer.

The adsorption and desorption pressures at any contact always agree to at least 1 in 10,000 and very often much better than that.

\section{B. ACCURACY IN ADSORPTION MEASUREMENTS AT HIGH PRESSURES}

This depends on the precision in the measurement of gas pressure, apparatus volume, experimental temperature, and helium density of the adsorbent and on the accuracy of the $P-V-T$ data for the adsorbate used in calculation. Volume calibration of the empty apparatus can be done best by careful weighing with pure 
mercury. The elaborate procedure for purification of mercury, followed by Michels in the van der Waals Laboratory, Amsterdam, has been described by Comings. ${ }^{90}$ Temperature of the thermostat in which the adsorption apparatus is kept immersed should be controlled and measured with an accuracy of at least $\pm 0.05^{\circ}$. Compressibility isotherm data for most gases in the range $0-150^{\circ}$ and pressures up to $3000 \mathrm{~atm}$, measured by Michels and coworkers, ${ }^{91}$ are accurate to 1 in 10,000 or better.

\section{Versatility of the Michels Pressure Balance}

In most high-pressure adsorption measurements the pressure has been measured with the Bourdon-type pressure gauge with an accuracy of only about \pm 2 psi $(0.14 \mathrm{~atm})$. The use of the free-piston-type Michels pressure balance $e^{27-29}$ in the 6-3000-atm range can ensure an accuracy of 1 in 10,000 in all pressure measurements. The additional advantage of the pressure balance is that it can maintain constant pressure as long as it is rotating freely; a slight rise or fall in the pressure in the apparatus due to desorption or adsorption will be automatically compensated by the piston of the balance going up or down. This also serves as a good indication to see if adsorption equilibrium in the system is reached or not.

The pressure balance, used as a measuring instrument and also as a manostat, will be very handy for studying kinetics of chemisorption or of gas reactions at high pressures. Either the volume change at constant pressure or pressure change at constant volume can be followed easily by simple manipulation of the balance. The pressure balance does not seem to have been used for this purpose so far.

\section{Helium-Density or Dead-Space Measurements}

In all volumetric methods and gravimetric methods (except in the McBain sorption balance) for highpressure adsorption, the free volume in the apparatus is either calculated from the helium density of the adsorbent or directly calibrated with helium at low pressures. If the pressure and temperature measurements and temperature control of the thermostat are sufficiently precise, the accuracy of the final results is limited by that of the helium-density or dead-space measurements for which there is still no method for getting an accuracy of better than 1 in 1000 . This, added to the uncertainties regarding the exact magnitude of the corrections to be applied to the dead-space value to account for the steric corrections for the helium atom and the adsorbate molecule (cf. section III.C

(90) E. W. Camings, "High Pressure Technology," McGraw-Hill Book Co., Inc., Niew York, N. Y., 1956, p 199.

(91) See A. Michels, et al., in numerous publications between 1926 and 1960, mostly in Physica (in English).

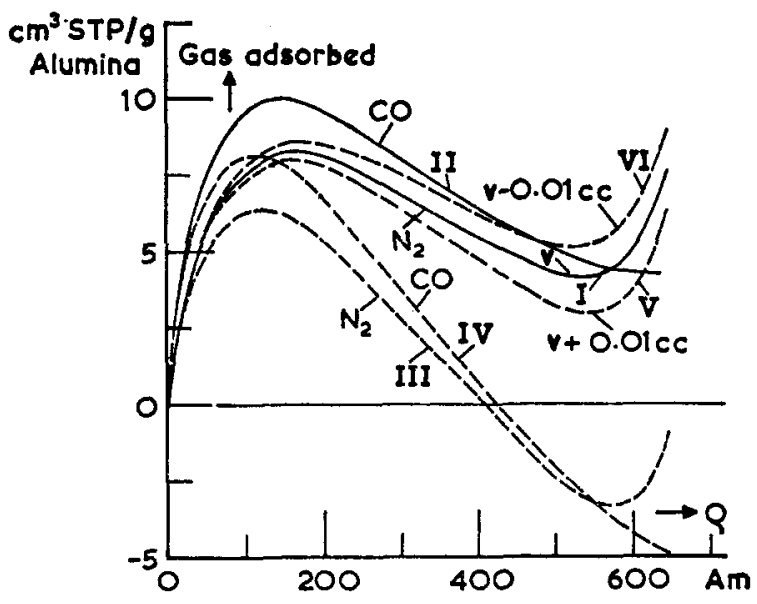

Figure 13. Shift in the adsorption isotherm $(\Delta g v s . \rho)$ if the dead-space value were different from the measured one. Curves I and II are adsorption isotherms (at pressures up to $3000 \mathrm{~atm}$ ) for $\mathrm{N}_{2}$ and $\mathrm{CO}$ on alumina at $25^{\circ}$ with the measured value for dead space; III and IV are the isotherms when steric correction is applied for helium only and not for the adsorbate molecules; V and VI are shifts of the $\mathrm{N}_{2}$ isotherm I when the value of the deadspace $v$ is arbitrarily increased or decreased by $0.01 \mathrm{~cm}^{3}$ (data of Menon ${ }^{81}$ ).

and D), constitutes the most serious limitation for the accuracy in high-pressure measurements.

Up to a gas density of 150 amagats the adsorption isotherm is not very sensitive to the exact value of the dead space in the apparatus, but at higher densities the dead-space value assumes greater importance, and above 350 amagats it becomes decisive for the shape of the adsorption isotherm. The second ascending and endothermic part of the nitrogen adsorption isotherms and the absence of this special feature in the adsorption of $\mathrm{CO}$ (both on alumina as adsorbent) remain qualitatively intact even when the dead-space value is arbitrarily increased or decreased or when corrections are applied to it; this clearly shows that they are not the projection of some experimental error in the dead-space value, magnified at high densities. Figure 13 illustrates this: slight changes in the dead-space value shift the high-density part of the adsorption isotherms upward or downward, but the essential qualitative fertures, especially the second ascending part of the nitrogen isotherms, are still preserved.

\section{SUGGESTIONS FOR FUTURE WORK}

An ideal adsorbent for high-pressure adsorption studies (a) should have fairly large surface area to get a measurable adsorption, (b) should not have too large a surface area so as to avoid presorption phenomena and also not to make the steric corrections too great, (c) must be able to withstand high pressures without undergoing serious contraction due to its compressibility or other dimensional changes on adsorption of gases on it. Alumina of surface area $100-200 \mathrm{~m}^{2} / \mathrm{g}$ will be a good choice to meet the above exacting conditions. 
Adsorbents like charcoal, coal, or activated carbon are definitely unsuitable, particularly at pressures above 100-200 atm. The BET surface area, pore-size distribution, pretreatment conditions, etc., for the adsorbent should be determined and clearly specified since the absence of such vital information in some cases makes it difficult to analyze and interpret the experimental adsorption isotherms.

High purity of the adsorbate gas, preferably mass spectrometrically pure, has also to be insisted upon in any serious high-pressure adsorption work. The reliability and accuracy of the compressibility data for the gas have also to be ensured before taking up any measurements, since the adsorbed amount is calculated from the density of the gas which in turn is derived from the experimentally measured pressure and the compressibility data for the gas.

Many systematic investigations have to be taken up on the chemisorption and kinetics of chemisorption of gases on solids at high pressures. For a better insight into the nature and behavior of the adsorbed phase, a very promising approach may be a study of the infrared spectra of adsorbed molecules under high pressures.

ACKNOWLEDGMENTS.-I am very much indebted to Professor A. Michels of van der Waals Laboratory, Amsterdam, under whose direction my high-pressure adsorption measurements of $\mathrm{N}_{2}$ and $\mathrm{CO}$ on alumina were carried out in 1956-1960. Some of the ideas discussed in this review were developed during the course of stimulating discussions with Professor J. H. de Boer during my stay in the Central Laboratory, Dutch State Mines, Geleen, in 1960-1961. For kind permission to reproduce figures, I am grateful to Professors E. Zielinski (Figures 7-9), M. V. C. Sastri (Figures 10 and 11), P. W. Selwood (Figure 12), the American Chemical Society (Figure 4), and the Royal Netherlands Chemical Society (Figure 3). I also express my thanks to Dr. G. S. Sidhu, Director of this laboratory, for his keen interest in this review. 